\title{
Alternative Oxidase Gene Family in Hypericum perforatum L.: Characterization and Expression at the Post-germinative Phase
}

\author{
Isabel Velada ${ }^{1 \dagger}$, Hélia G. Cardoso ${ }^{1 * t}$, Carla Ragonezi ${ }^{1}$, Amaia Nogales ${ }^{2}$, \\ Alexandre Ferreira ${ }^{1}$, Vera Valadas ${ }^{1}$ and Birgit Arnholdt-Schmitt ${ }^{3 \star}$ \\ 1 ICAAM - Instituto de Ciências Agrárias e Ambientais Mediterrânicas, Laboratório de Biologia Molecular, Universidade de \\ Évora, Pólo da Mitra, Évora, Portugal, ${ }^{2}$ Linking Landscape, Environment, Agriculture and Food, Instituto Superior de \\ Agronomia-Universidade de Lisboa, Lisboa, Portugal, ${ }^{3}$ EU Marie Curie Chair, ICAAM - Instituto de Ciências Agrárias e \\ Ambientais Mediterrânicas, Universidade de Évora, Pólo da Mitra, Évora, Portugal
}

OPEN ACCESS

Edited by:

Gregory Franklin

Institute of Plant Genetics of the Polish Academy of Science, Poland

Reviewed by:

Marina Gavilanes-Ruiz, Universidad Nacional Autónoma de

México, Mexico

Daniel H. Gonzalez,

Universidad Nacional del Litoral,

Argentina

*Correspondence:

Hélia G. Cardoso

hcardoso@uevora.pt

Birgit Arnholdt-Schmitt

eu_chair@uevora.pt

${ }^{\dagger}$ These authors have contributed equally to this work.

Specialty section

This article was submitted to Plant Metabolism and Chemodiversity,

a section of the journal

Frontiers in Plant Science

Received: 16 March 2016

Accepted: 04 July 2016

Published: 11 August 2016

Citation:

Velada I, Cardoso HG, Ragonezi C, Nogales A, Ferreira A, Valadas $V$ and Arnholdt-Schmitt B (2016) Alternative

Oxidase Gene Family in Hypericum

perforatum L.: Characterization and

Expression at the Post-germinative

Phase. Front. Plant Sci. 7:1043

doi: 10.3389/fpls.2016.01043
Alternative oxidase $(A O X)$ protein is located in the inner mitochondrial membrane and is encoded in the nuclear genome being involved in plant response upon a diversity of environmental stresses and also in normal plant growth and development. Here we report the characterization of the AOX gene family of Hypericum perforatum L. Two AOX genes were identified, both with a structure of four exons (HpAOX1, acc. KU674355 and HpAOX2, acc. KU674356). High variability was found at the $\mathrm{N}$-terminal region of the protein coincident with the high variability identified at the mitochondrial transit peptide. In silico analysis of regulatory elements located at intronic regions identified putative sequences coding for miRNA precursors and trace elements of a transposon. Simple sequence repeats were also identified. Additionally, the mRNA levels for the HpAOX1 and HpAOX2, along with the ones for the HpGAPA (glyceraldehyde-3-phosphate dehydrogenase A subunit) and the HpCAT1 (catalase 1), were evaluated during the post-germinative development. Gene expression analysis was performed by RT-qPCR with accurate data normalization, pointing out HpHYP1 (chamba phenolic oxidative coupling protein 1) and $\mathrm{HpH}_{2} \mathrm{~A}$ (histone 2A) as the most suitable reference genes (RGs) according to GeNorm algorithm. The HpAOX2 transcript demonstrated larger stability during the process with a slight down-regulation in its expression. Contrarily, HpAOX1 and HpGAPA (the corresponding protein is homolog to the chloroplast isoform involved in the photosynthetic carbon assimilation in other plant species) transcripts showed a marked increase, with a similar expression pattern between them, during the post-germinative development. On the other hand, the HpCAT1 (the corresponding protein is homolog to the major $\mathrm{H}_{2} \mathrm{O}_{2}$-scavenging enzyme in other plant species) transcripts showed an opposite behavior with a down-regulation during the process. In summary, our findings, although preliminary, highlight the importance to investigate in more detail the participation of $A O X$ genes during the post-germinative development in $H$. perforatum, in order to explore their functional role in optimizing photosynthesis and in the control of reactive oxygen species (ROS) levels during the process.

Keywords: cyanide-resistant pathway, St. John's Wort, plant development, gene expression, transposable elements, miRNAs, alternative oxidase, post-germination 


\section{INTRODUCTION}

Hypericum perforatum L., (St. John's Wort) is a wide spread species found throughout all temperate regions of north and south hemispheres (Robson, 1977). Natural populations are usually observed in abandoned fields, along roadsides or in overgrazed rangelands (Maron et al., 2007). Its high interest for the pharmaceutical industry, due to its medicinal properties attributed to the presence of metabolites with an antidepressive, anticancer, and antiviral action (Zanoli, 2004; Gartner et al., 2005; Kubin et al., 2005), leads to a gradual re-expanding of field cultivation in Western Europe since the nineties.

Nevertheless, breeding of medicinal plants was neglected for a long time and has been initiated only about 20 years ago with special efforts in North-Europe. Homogeneous plantations are expected to provide farmers not only with higher yield stability, but also with increased homogeneity in product quality which in terms of medicinal plants would correspond to the composition of effective plant extracts. In this view, adequate technologies are being requested, especially the ones related with the control of seed germination, seedling development, and growth. Thus, fundamental and applied research can help to identify efficient strategies to reach this goal.

Marker assisted selection (MAS) is a process commonly used in plant breeding programs by which the selection of desirable phenotypic characteristics with agronomic interest, known as agronomic traits, is achieved indirectly by using DNA markers, closely linked to underlying gene(s), or developed from a specific gene(s). The last ones, named functional markers (FM), can be used to find out allelic variation in the genes underlying a trait, contributing to increase efficiency and accuracy of plant breeding programs, reason why have been gaining increasing attention during the last years (Andersen and Lübberstedt, 2003; Neale and Savolainen, 2004; Arnholdt-Schmitt, 2005). The identification of candidate genes is recognized as the first step for FM development. These genes can be found out by high-through-put differential gene expression analyses or by hypothesis-driven research approaches, which actually represent the most promising strategies in molecular plant breeding (Arnholdt-Schmitt, 2005; Collins et al., 2008). Alternative oxidase $(A O X)$ was previously pointed out as a potential source for FM development related with plant plasticity under environmental stress, which means genotypes able to better succeed across variable conditions (Arnholdt-Schmitt et al., 2006; Clifton et al., 2006; Cardoso and Arnholdt-Schmitt, 2013) and have been also related to plant developmental processes (Campos et al., 2009, 2016; Santos Macedo et al., 2009).

AOX is a mitochondrial membrane protein acting as a terminal oxidase in the alternative (cyanide-resistant) respiratory pathway, where it reduces oxygen to water (Umbach et al., 2002). AOX allows continued turnover of carbon skeletons through glycolysis and the tricarboxylic acid (TCA) cycle when the cytochrome pathway is saturated, functioning as an overflow enzyme in the electron transport chain (ETC). However, even when the cytochrome pathway is not saturated, AOX may be activated in order to maintain balanced oxidation/reduction reactions and a balanced carbon metabolism (Rhoads et al., 1998 and references therein). AOX controls the formation of mitochondrial reactive oxygen species (ROS) and prevents specific components of the respiratory chain from overreduction, thereby relieving oxygen species (OS) originated from environmental stresses (Popov et al., 1997; Amirsadeghi et al., 2007). Many reports show the involvement of AOX in plant response upon a diversity of biotic and abiotic stresses establishing the link between AOX and its role on the control of cellular ROS levels (see review Vanlerberghe, 2013). Other antioxidative enzymes are also implicated in the control of cellular ROS levels. Catalase (CAT), the major $\mathrm{H}_{2} \mathrm{O}_{2}$-scavenging enzyme in all aerobic organisms (Mhamdi et al., 2010), performs the rapid removal of $\mathrm{H}_{2} \mathrm{O}_{2}$ from the cell by oxidation of $\mathrm{H}_{2} \mathrm{O}_{2}$ to $\mathrm{H}_{2} \mathrm{O}$ and $\mathrm{O}_{2}$ (Møller et al., 2007). Nevertheless, ROS are not only involved in plant response upon stress conditions, they have also an active play in normal physiological processes such as in seed germination and in dormancy alleviation (Kwak et al., 2006; Bailly et al., 2008; Oracz et al., 2009). The ability of seeds to germinate might be related to their capacity to regulate ROS levels produced during mitochondrial oxygen consumption, and to neutralize the pro-oxidant activities of allelochemicals present in the medium (Pergo and Ishii-Iwamoto, 2011). It is expected that AOX, like other antioxidative enzymes, would be involved in the process of seed germination and seedling development by the control of ROS produced during the germination process, and besides also in the promotion of cellular homeostasis under the large metabolic changes that take place during germination and post-germination development. The process of seed germination starts when dry seeds get in touch with water under favorable conditions (imbibition), and it ends when radicle penetrates seed covering layers and is observable, followed by seedling establishment (Weitbrecht et al., 2011).

The step forward corresponds to seedling development (growth and differentiation). AOX has been implicated in the regulation of the mechanim of cell-reprogramming by improving metabolic transitions associated to the flexible carbon balance (Arnholdt-Schmitt et al., 2006; Rasmusson et al., 2009). Several authors have shown that regulation of soybean $A O X$ genes depend on the post-germinative development of soybean cotyledons (Finnegan et al., 1997; McCabe et al., 1998). In some plants, cyanide-insensitive respiration is required for germination (reviewed by Botha et al., 1992). For example, in cocklebur, the alternative pathway was activated after imbibition of seeds (Esashi et al., 1981; Saisho et al., 2001).

Considering this previous knowledge, this study aimed to isolate and characterize the $H$. perforatum $A O X$ gene family to then be able to explore, by in silico analysis, the existence of regulatory elements located at intronic regions. Also, to investigate at the mRNA level the expression of the AOX gene family members during the postgerminative development along with two other proteins know to be involved, in other plant species, in different pathways: CAT1 involved in the control of ROS levels and chloroplast glyceraldehyde-3-phosphate dehydrogenase A subunit (GAPA) involved in the photosynthetic carbon assimilation. 


\section{MATERIALS AND METHODS}

\section{HpAOX Gene Member's Identification and Isolation \\ Isolation of Complete HpAOX Genes}

Complete $A O X$ gene isolation was performed in several steps. First, partial gene isolation was performed using degenerated P1 and P2 primers following the protocol previously described by Saisho et al. (1997). Genomic DNA (gDNA) used as template in the PCR was extracted from 1 month old seedlings (bulked of eight seedlings previously established under in vitro conditions) using the DNeasy Plant Mini Kit (Qiagen, Hilden, Germany) according to the manufacturer's protocol. PCR was conducted with the Ready-To-Go PCR Beads (GE Healthcare, Little Chalfont, England) using $10 \mathrm{ng}$ of gDNA and $0.2 \mu \mathrm{M}$ of each primer. PCR was carried out for 35 cycles in the 2770 thermocycler (Applied Biosystems, Foster City, CA, USA).

In a second step, the $5^{\prime}$ and $3^{\prime}$ ends of the isolated $H p A O X$ gene fragments were determined by $5^{\prime}$ and $3^{\prime}$ RACE-PCRs. For this, total RNA was extracted, from the same material used for gDNA extraction, using the RNeasy Plant Mini Kit (Qiagen, Hilden, Germany) with on-column digestion of DNA applying the RNase-Free DNase Set (Qiagen, Hilden, Germany), according to manufacturer's protocol.

For $3^{\prime}$ end isolation, a cDNA single strand was produced by RevertAid ${ }^{\mathrm{TM}}$ HMinus First Strand cDNA Synthesis kit (Fermentas, Ontario, Canada) according to manufacturer's instructions with oligo $\mathrm{d}(\mathrm{T})$ primer (Roche, Mannheim, Germany) and $5 \mu \mathrm{g}$ of total RNA. 3'RACE-PCR was conducted using $1 \mu \mathrm{l}$ of cDNA single strand as template with the reverse primer VIAL 9 (Roche, Mannheim, Germany) and a gene-specific forward primer (see sequence on Table S1).

For $5^{\prime}$ end isolation, $1 \mu \mathrm{g}$ of total RNA was used to synthesize the first-strand cDNA using the SMARTer ${ }^{\mathrm{TM}}$ RACE cDNA Amplification kit (Clontech Laboratories, Inc., Mountain View, CA, USA) according to manufacturer's instructions. 5'RACEPCR was carried out using $0.2 \mu \mathrm{M}$ of the reverse gene specific primer (Table S1) following protocol provided with the kit.

Finally, for the complete gene isolation, gDNA and total RNA were isolated from a single in vitro growing plantlet following the procedures described above. One gene-specific primer set was designed for each $H p A O X$ gene (see Table S1) based on the previously isolated $5^{\prime}$ and $3^{\prime}$-UTR sequences. Ten nanograms of gDNA or $1 \mu \mathrm{l}$ of oligo d(T) first strand cDNA were used as template with $0.2 \mu \mathrm{M}$ of each specific primer. PCRs were performed using Phusion ${ }^{\mathrm{TM}}$ High-Fidelity DNA Polymerase (Finnzymes, Espoo, Finland) according to the manufacturer's protocol (see annealing temperatures at Table S1).

\section{Cloning and Sequence Analysis}

PCR fragments were separately cloned into a pGem ${ }^{\circledR}$-T Easy vector (Promega, Madison, USA) and used to transform E. coli JM109 (Promega Madison, WI, USA) competent cells. Plasmid DNA was further extracted from putative recombinant clones by alkaline lysis protocol (Bimboim and Doly, 1979) and sense and antisense strands were sequenced (Macrogen company: www.macrogen.com) using primers T7 and SP6 (Promega, Madison, USA).

Sequence homology was searched in the NCBI databases (National Center for Biotechnology Information, Bethesda, MD) using BLAST algorithm (Karlin and Altschul, 1993; http://www.ncbi.nlm.nih.gov/; BLASTn and BLASTp).

CLC Main Workbench 7.5.1 software (ClCbio, Aarhus $\mathrm{N}$, Denmark) was used to edit HpAOX sequences (cDNA, gDNA and putative translated peptide). Intron location was made using the software Spidey (http://www.ncbi.nlm.nih.gov/IEB/Research/Ostell/Spidey/).

Gene draw was performed in FancyGene 1.4 (Rambaldi and Ciccarelli, 2009), freely available at http://bio.ieo.eu/fancygene/.

Sequences were aligned in MUSCLE (http://www.ebi.ac.uk/Tools/msa/muscle/) following the standard parameters. Phylogenetic reconstruction was performed in MEGA software (Tamura et al., 2007) by NeighborJoining $(\mathrm{NJ})$ and the inferred tree was tested by bootstrap analysis using 1000 replicates. Graphical view was edited in the Fig Tree v14.0 software (http://tree.bio.ed.ac.uk/software/figtree/). The free available TargetP software (Emanuelsson et al., 2000) was used to predict the protein subcellular localization and the position of the cleavage sites of mitochondrial targeting signals (http://www.cbs.dtu.dk/services/TargetP/).

\section{In silico Identification of Regulatory Elements Located at the HpAOX Intronic Regions}

For the identification of putative miRNA precursor sequences located at the $H p A O X$ introns, the publicly available software miR-abela (http://www.mirz.unibas.ch/cgi/pred_miRNA_genes.cgi) was used. MiPred software was used (http://server.malab.cn/MiPred/; Jiang et al., 2007) to validate potential pre-miRNAs and the web-based software Mfold, (available at http://mfold.rit.albany.edu/?q=mfold/RNA-Folding-Form;

Zuker, 2003) applied in the prediction of the secondary structure of pre-miRNA. To screen potential miRNAs candidates, the previous validated pre-miRNA sequences were analyzed with the software miRBase (http://www.mirbase.org/search.shtml). BLASTx from NCBI database (http://www.ncbi.nlm.nih.gov/BLAST/) was used to find the potential target genes (Mathews et al., 1999; Zuker, 2003).

For identification of transposable elements (TE) putatively located at the intronic regions of $H p A O X$, the CENSOR software tool from the Genetic Information Research Institute-GIRI (http://www.girinst.org/censor/index.php) was used (Kohany et al., 2006). For identification of simple sequence repeats (SSRs) the RepeatMasker platform was used (http://www.repeatmasker.org/; Smit et al., 2013-2015).

\section{HpAOX Transcript Quantification} Plant Material and Experimental Conditions

In order to evaluate the role of $A O X$ genes in $H$. perforatum postgerminative development an experiment was conducted. Seeds were collected from the achenes of a mother plant growing in the field (Viana do Alentejo, Portugal, $38^{\circ} 21^{\prime} 37^{\prime \prime} \mathrm{N}, 7^{\circ} 59^{\prime} 13^{\prime \prime} \mathrm{W}$ ). 
No specific licenses were needed for achene harvesting since $H$. perforatum is not a protected species. Seeds were inoculated in vitro after their disinfection (see details in Ferreira et al., 2009) and maintained during a period of 14 days under $16 \mathrm{~h}$ photoperiod, constant day/night temperature of $25^{\circ} \mathrm{C}$, and 80 $\mu \mathrm{mol} \mathrm{m}{ }^{-2} \mathrm{~s}^{-1}$ of light intensity (Philips fluorescent lamps).

Samples were collected at different time points: 4, 6, $8,10,12$, and 14 days after sowing (Figure 1). Samples collected between 4 and 8 days consisted in a bulked sample of $\sim 50$ explants. Samples collected between 10 and 14 days represented a set of $\sim 10$ seedlings for each time point.

\section{RNA Isolation and First-Strand cDNA Synthesis}

Total RNA was extracted with the RNeasy Plant Mini Kit (Qiagen, Hilden, Germany), according to the manufacturer's instructions, and eluted in $30 \mu \mathrm{l}$ volume of RNase-free water. Possible residual genomic DNA present in RNA samples was digested with the DNase I (RNase-Free DNase Set, Qiagen, Hilden, Germany), following the manufacturer's instructions. The RNA concentration was assessed with the NanoDrop-2000C spectrophotometer (Thermo Scientific, Wilmington, DE, USA), and the RNA integrity was checked, based on the presence of the two ribosomal subunits, by agarose gel electrophoresis in a Gene Flash Bio Imaging system (Syngene, Cambridge, UK). Maxima First Strand cDNA Synthesis Kit for RTqPCR (Thermo Scientific, Wilmington, DE, USA) was used to synthesize complementary DNA (cDNA) from RNA samples (using $1 \mu \mathrm{g}$ of total RNA), according to the manufacturer's instructions.

\section{Quantitative Real-Time PCR}

Real-time PCR was performed in the Applied Biosystems 7500 Real-Time PCR System (Applied Biosystems, Foster City, CA, USA). Real-time PCR reactions were carried out using 1X Maxima SYBR Green qPCR Master Mix, $300 \mathrm{nM}$ of forward and reverse primers, and $1.25 \mathrm{ng}$ of cDNA in a total volume of 18 $\mu$ l. Primers for the 11 genes analyzed here were designed based on the $H$. perforatum sequences deposited in the NCBI with the Primer Express v3.0 (Applied Biosystems, Foster City, CA, USA), using the default parameters of the software (Table 1). All primer pairs were evaluated for their probability to form dimers and secondary structures using the proper tool of the software for the purpose. The following thermal profile was applied: $10 \mathrm{~min}$ at $95^{\circ} \mathrm{C}$, and 40 cycles of $15 \mathrm{~s}$ at $95^{\circ} \mathrm{C}$ and $60 \mathrm{~s}$ at $60^{\circ} \mathrm{C}$. Possible contaminations and primer dimers formation were discarded by using no-template controls (NTCs). A standard curve with four points was performed using the undiluted pool containing all cDNA samples and three 5-fold serial dilutions. All samples were run in duplicate. A melting curve analysis was performed to guarantee amplification of specific products. The values of quantification cycles $\left(\mathrm{C}_{\mathrm{q}}\right)$ were obtained for each sample with the Applied Biosystems 7500 software (Applied Biosystems, Foster City, CA, USA).

\section{Determination of Reference Gene Expression Stability Using GeNorm Algorithm}

GeNorm algorithm was used to determine the expression stability of each candidate reference gene (RG). The input data for GeNorm algorithm were the relative quantities (RQ) calculated with the $\mathrm{Cq}$ value for each sample by the delta-Ct method using the formula $\mathrm{RQ}=\mathrm{E}^{\Delta \mathrm{Cq}}$, where $\mathrm{E}$ is the amplification efficiency calculated for each primer pair and $\Delta \mathrm{C}_{\mathrm{q}}=$ lowest $\mathrm{C}_{\mathrm{q}}$ sample $\mathrm{C}_{\mathrm{q}}$ (Vandesompele et al., 2002). Amplification efficiency (E) was calculated using the formula $E=10^{(-1 / \text { slope })}$ where the slope value was given by the Applied Biosystems (AB) software. GeNorm determines the pairwise variation ( $V$; Vandesompele et al., 2002) and in the present study $V$ values were determined for the candidate RGs using a cut-off value of 0.15 , below which the inclusion of an additional RG is not required for normalization. In this way, GeNorm also determines the optimal number of genes required to calculate a reliable normalization factor.
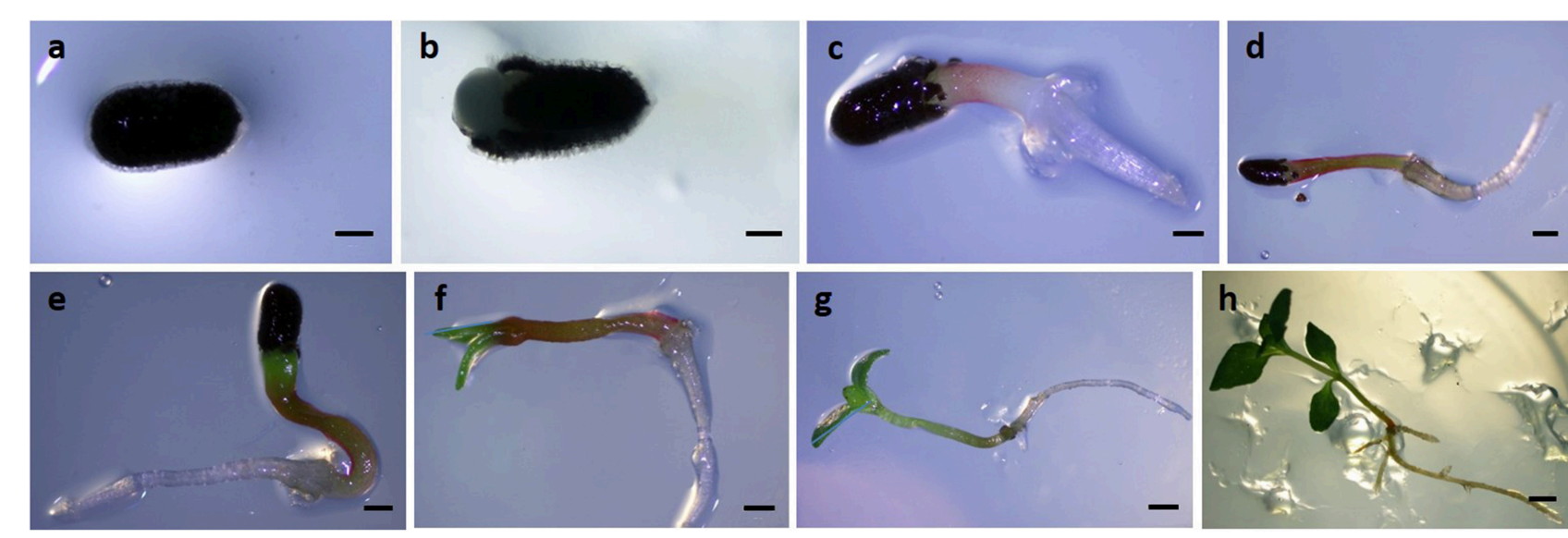

FIGURE 1 | Seed germination and post-germinative development of seedlings in Hypericum perforatum. (A) 0 days, (B) 2 days, (C) 4 days, (D) 6 days, (E) 8 days, (F) 10 days, (G) 12 days, (H) 14 days post-sowing. Bars: $(\mathbf{A}-\mathbf{C})=0,5 \mathrm{~mm}$; (D-G) $=1 \mathrm{~mm} ;(\mathbf{H})=5 \mathrm{~mm}$. 
TABLE 1 | Primer sequences and other parameters for the genes used in this study.

\begin{tabular}{|c|c|c|c|c|}
\hline Gene (acc. no.) & Primer Sequence $\left(5^{\prime}-3^{\prime}\right)$ & AL (bp) & $\operatorname{Tm}\left({ }^{\circ} \mathrm{C}\right)$ & $r^{2} / \mathrm{E}(\%)$ \\
\hline \multirow[t]{2}{*}{ Hp18SrRNA (AF206934) } & Fw: CGTCCCTGCCCTITGTACAC & 72 & 80.23 & $0.999 / 94.50$ \\
\hline & Rv: CGAACACTTCACCGGACCAT & & & \\
\hline \multirow[t]{2}{*}{ Hp26SrRNA (DQ110887) } & Fw: GCGTTCGAATTGTAGTCTGAAGAA & 65 & 80.79 & 0.999/90.65 \\
\hline & Rv: CGGCACCCCCTTCCAA & & & \\
\hline \multirow[t]{2}{*}{ HpGAPA (EU301783) } & Fw: GGTCGACTTCAGGTGCAGTGA & 76 & 81.04 & $0.999 / 83.88$ \\
\hline & Rv: CACCATGTCGTCTCCCATCA & & & \\
\hline \multirow[t]{2}{*}{ HpGSA (KJ624985) } & Fw: GCAATAATCCTTGAACCTGTTGTG & 78 & 78.35 & $0.992 / 94.30$ \\
\hline & Rv: CCTGCGGAGAGCGTTGA & & & \\
\hline \multirow[t]{2}{*}{ HpHYP1 (JF774163) } & Fw: GGAGGAAGCAAGGGTAAGATTACA & 81 & 77.18 & $0.997 / 93.97$ \\
\hline & Rv: CCCGATCTTGACTTCTTCTTCATT & & & \\
\hline \multirow[t]{2}{*}{ HpH2A (EU034009) } & Fw: CCGGTTGGGAGGGTTCA & 63 & 79.64 & $0.995 / 95.01$ \\
\hline & Rv: TGCACCGACCCTTCCATT & & & \\
\hline \multirow[t]{2}{*}{ HpRBCL (HM850066) } & Fw: CGCGGTGGGCTTGATT & 71 & 76.86 & $0.999 / 98.95$ \\
\hline & Rv: CGATCCCTCCATCGCATAAA & & & \\
\hline \multirow[t]{2}{*}{ HpTUB (KJ669725) } & Fw: GGAGTACCCTGACAGAATGATGCT & 80 & 77.89 & $0.990 / 93.48$ \\
\hline & Rv: TTGTACGGCTCAACAACAGTATCC & & & \\
\hline \multirow[t]{2}{*}{ HpAOX1 (EU330415) } & Fw: TTGGACAATGGCAACATCGA & 69 & 80.11 & $0.995 / 90.46$ \\
\hline & Rv: GGGAGGTAGGCGCCAGTAGT & & & \\
\hline \multirow[t]{2}{*}{ HpAOX2 (EU330413) } & Fw: TCAACGCCTACTITGTGATCTATCTC & 80 & 78.47 & $0.998 / 95.03$ \\
\hline & Rv: AATGGCCTCTTCTTCCAAATAGC & & & \\
\hline \multirow[t]{2}{*}{ HpCAT1 (AY173073) } & Fw: CGCTTCCTCAACAGATGGATTAG & 71 & 79.10 & $0.996 / 96.45$ \\
\hline & Rv: ACCCAGATGGCTCTGATITCA & & & \\
\hline
\end{tabular}

acc. no., NCBI accession number; AL, amplicon length; Tm, melting temperature for each amplicon; $r^{2}$, correlation coefficient; E, PCR efficiency.

\section{Analysis of Transcript Expression}

For expression levels normalization of the genes under study, $\mathrm{C}_{\mathrm{q}}$ values were converted into RQ by the delta-Ct method, as described in previous section. The normalization factor was determined by the GeNorm algorithm and corresponds to the geometric mean between the relative quantities of the selected RGs, for each sample. For each gene of interest, the normalized value of gene expression is obtained by doing the ratio between the relative quantities and the corresponding normalization factor, for each sample. Graphics indicate the mean \pm standard deviation of three biological replicates. The control group (4 dps) was set to 1 and the bars corresponding to the other time points show the fold-change with respect to $4 \mathrm{dps}$. The $t$-test method [IBM ${ }^{\circledR}$ SPSS $^{\circledR}$ Statistics version 22.0 (SPSS Inc., USA)] was used to ascertain statistical significances $(p \leq 0.05$ and $p \leq$ 0.01 ) between means.

\section{RESULTS}

\section{Characterization of the Full-Length Sequences of HpAOX Gene Family}

The use of $\mathrm{P} 1 / \mathrm{P} 2$ primers allowed the isolation of amplicons with 444 bp length showing high homology with $A O X$ genes from other plant species, which was expected considering the previous identification of $A O X$ genes using this degenerated primer pair not only in Arabidopsis thaliana (Saisho et al., 1997) but also in several other plant species (Campos et al., 2009; Costa et al., 2009; Frederico et al., 2009; Santos Macedo et al., 2009) where it is included $H$. perforatum with three $A O X 1$ gene members and a single AOX2 (Ferreira et al., 2009). However, the use of ampliconspecific primers located at $5^{\prime}$ and $3^{\prime}$ ends allowed the isolation of the full-length cDNA sequences from only two $H p A O X$ genes. After several attempts it was possible to confirm the existence of only two $A O X$ gene members in $H$. perforatum, one belonging to the $A O X 1$-subfamily and another to the AOX2-subfamily.

Gene size variability was identified at cDNA level in both genes. $5^{\prime}$ end showed variability among sequences of the same gene. In the case of $H p A O X 1$, the length of $5^{\prime}$ end ranged between 26 and 116 bp (Figure S1), and in HpAOX2 it ranged between 56 and $111 \mathrm{bp}$ (Figure S2). Sequence size variability was also detected at $3^{\prime}$ end of the $H p A O X 1$ ranging between 159 and 227 bp (Figure S3). The larger sequences are presented in Figures S4, S5.

The AOX1 gene at cDNA level isolated from $H$. perforatum (deposited at the NCBI with the acc. EU330415.2) has 1415 bp (Figure S4) and presents an open reading frame (ORF) of $1056 \mathrm{bp}$, which encodes a putative polypeptide with 351 amino acid residues. The AOX2-subfamily member, $H p A O X 2$ (acc. EU330413.2), presents $1311 \mathrm{bp}$ and an ORF of 1017 bp encoding a putative polypeptide with 338 amino acid residues (Figure S5). The first ATG codon found in the beginning of the resultant ORF of $H p A O X 1$ represents the correct initiation of translation. In the $H p A O X 2$ two putative start codons were detected, one generating a larger peptide (with more 18 amino acid residues, see Figure S2). However, no similarity with other plant species was observed on that region which lead us to select a sequence encoding the shorter sequence. Figures S4, S5 indicate the cDNA sequences 
for both genes including the putative translated peptide and the conserved sites for intron positions. The difference in the overall length for the complete ORF sequences is mostly due to the size variability at exon 1 in the $\mathrm{N}$-terminal region. Exon 1 has a size of 378 bp for HpAOX1 and 339 bp for HpAOX2.

Forward and reverse primers located at $5^{\prime}$ and $3^{\prime}$ gene ends, respectively, were used at genomic level and allowed the isolation of HpAOX1 gene with $2825 \mathrm{bp}$ and HpAOX2 with $2213 \mathrm{bp}$. Gene structure, common to both $H p A O X$ genes, is composed by four exons interrupted by three introns (Figure 2). The conservation of exons size is here confirmed for the three last exons (exon 2: 129, exon 3: 489, and exon 4: $57 \mathrm{bp}$ ). Contrarily to this conservation at the exons, high level of variability in intronic regions was observed. Intron 1, intron 2, and intron 3 of $H p A O X 1$ are 261, 831, and 99 bp long, respectively, while in HpAOX2 they are 699,202 , and 181 bp long, respectively. This variability was observed within a gene and across gene members from the $A O X$ subfamily/family at species level and across species (Figure 2).

The homologous identity score obtained with the deduced amino acid residue sequence revealed that both $H p A O X 1$ and HpAOX2 share a great similarity with other AOX proteins, like AOX1a from Arabidopsis thaliana (acc. NP_188876.1, $70 \%$ ) and AOX2 from Vitis vinifera (acc. NP_001268001.1, $71 \%$ ), respectively. To determine the relationship between both $H p A O X$ genes and $A O X$ from other eudicot plant species a NJ tree was constructed using the 153 translated AOX sequences from both eudicot and monocot plant species (Figure 3). A clear separation between both $A O X$-subfamilies could be seen forming the two main clusters (in blue the $A O X 1$-subfamily and in green the $A O X 2$-subfamily). Each $H p A O X$ member was grouped in each $A O X$-subfamily. Monocot $A O X 1$ members form a separated group within the cluster of the $A O X 1$-subfamily. Gene members from species that belong to the same family also group in separated clusters within each subfamily. A syntheny plot to the AOX gene family (HOM03D001776) across whole genomes available at PLAZA 3.0 and Phytozome v11.0 showed that $A O X$ genes occur mainly as a single copy gene in sense or reverse orientation. Some cases of tandem duplication events are also reported. In the NJ tree it is possible to see that translated peptides corresponding to those duplicated events are not always grouped together (examples are highlighted in blue). Sequences of Salix purpurea are tandem repeats in which two sequences group together (SapurV1A.1470s0080.1 and SapurV1A.0346s0170.1) and another not (SapurV1A.0377s0140.1.p and SapurV1A. 0377s0150.1.p). A second example are the sequences of A. thaliana (AT3G22360.1 and AT3G22370.1) which share more similarity with sequences of other plant species.

A multiple sequence alignment, constructed using complete AOX sequences from plant species including both $H p A O X$ deduced sequences (HpAOX1 and HpAOX2), allowed us to highlight similarities and differences in the protein sequences (Figure S6). The predicted cleavage site length of the mitochondrial transit peptide (mTP) from the start of the protein is highlighted in blue boxes for all sequences included in the alignment. A great variation on the predicted length of this region can be seen, going from 8 amino acids in AtAOX1b (acc. AT3G22360) to 72 amino acids in AtAOX2 (acc. AT5G64210). Both HpAOX proteins were predicted to be located in the mitochondria (mit score of $76 \%$ for $H p A O X 1$ and $87 \%$ for HpAOX2).

Helices $\alpha 1$ and $\alpha 4$ (in red in Figure S6) that make part of the hydrophobic region of the AOX molecular surface demonstrated high degree of variability when compared with helices $\alpha 2, \alpha 3$, $\alpha 5$, and $\alpha 6$ (in green in Figure S6) which form the four-helix bundle. The helix $\alpha 4$ is slightly more conserved than $\alpha 1$. In fact, low level of similarity can be seen at the N-terminal region, not only related with differences in size (shown by the presence of minus signs) due to exon 1 variability reported above, but also due to different amino acid composition (shown by the presence

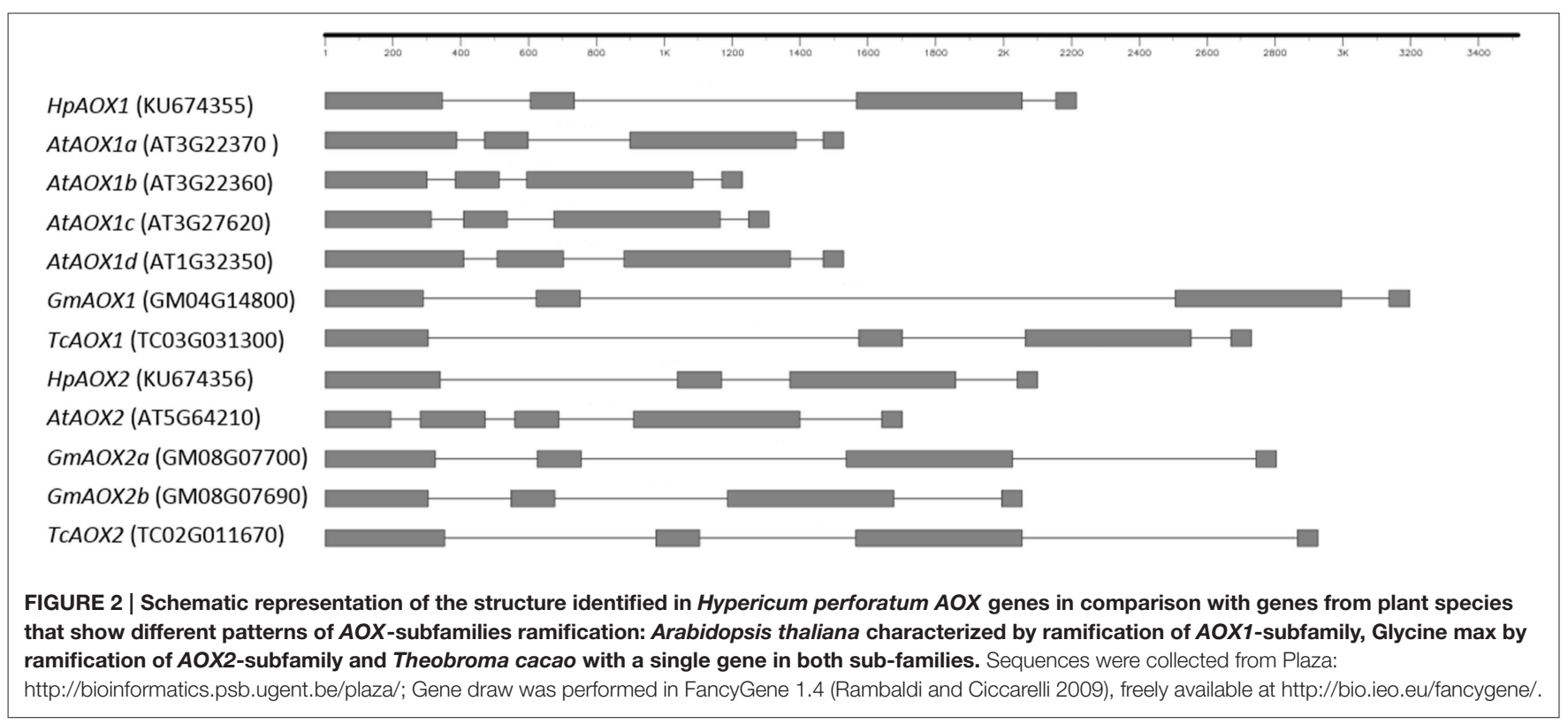




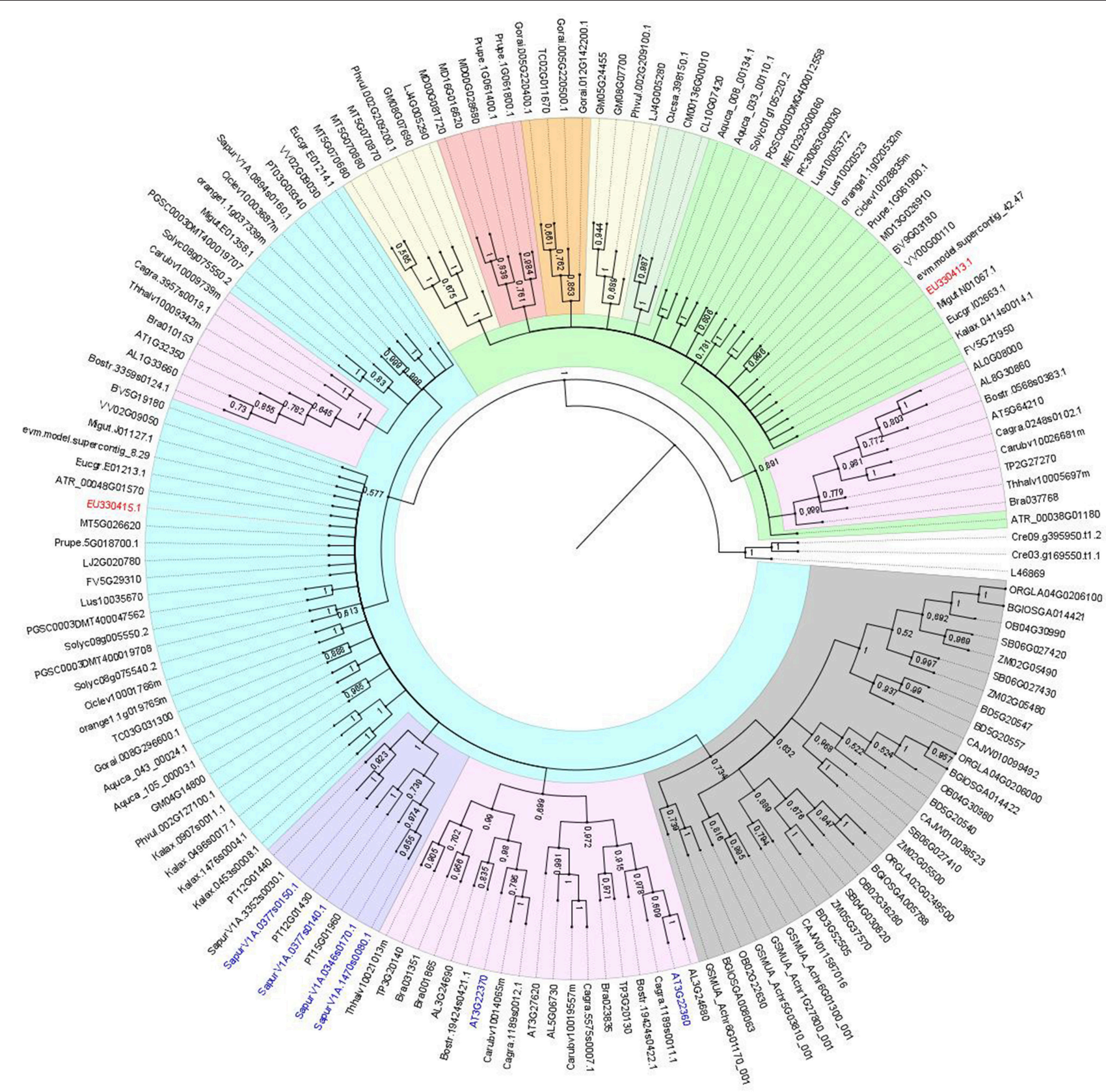

FIGURE 3 | Neighbor-Joining (NJ) tree showing the relationships among deduced AOX sequences from 45 plant species, including monocot and eudicot plant species. Both AOX sequences of Hypericum perforatum were included (in red). 153 AOX sequences from higher plants were included (correspondence of accession numbers and the plant species is included in Tables S2, S3). The NJ tree was obtained using the complete peptide sequences. The alignments were bootstrapped with 1000 replicates by the NJ method using the MEGA 6 software. AOX sequence from Neurospora crassa and two sequences of Chlamydomonas reinhardtii were used as outgroup. The scale bar indicates the relative amount of change along branches. In blue the branch corresponding to the AOX1-subfamily and in green the branch corresponding to the AOX2-subfamily. In yellow the branch corresponding to the AOX1d.

of amino acids colored in red). Increase in the similarity, at both levels (sequence composition and size conservation), starts near the conserved regulatory cystein residue I (CysI). All main features that characterize AOX proteins are equally conserved at both HpAOX peptide sequences. There are examples, the four universally conserved glutamate residues (E) and the two universally conserved histidine $(\mathrm{H})$ residues, and the amino acid residues that interact with the protein inhibitor located 
at helix $\alpha 5$. In silico analysis searching for regulatory elements lead us to the identification of simple sequence repeats (SSR) in intronic regions of $H p A O X 1$ : a 59 bp long TTTAT motif in intron 1 and a $32 \mathrm{bp}$ long AT motif in intron 2, and of $H p A O X 2$ : a 44 bp long CGGAGG motif located at exon 1 (location of SSRs are presented in Figures S7, S8 of Supplementary material). CENSOR software detected a region of $119 \mathrm{bp}$ in the HpAOX2 sequence with similarity to the LTR region of a Cassandra MT-LTR retrotransposon from Medicago truncatula. RepeatMasker software also found a positive match of this fragment with a Cassandra LTR from Zea mays. A blast search in the NCBI databases using that previous identified sequence revealed a $72 \%$ homology to a Pisum sativum Cassandralike LTR.

Additionally, a search for putative miRNA precursor sequences (pre-miRNAs) identified one putative pre-miRNA located at intron 1 and two pre-miRNAs at intron 2 of $H p A O X 1$ (Table 2). Potential candidates for miRNAs were identified with homology with miRNAs previously described in other plant species. The pre-miRNA at intron 1 revealed homology with the gma-miR5780c; the pre-miRNAs at intron 2 revealed homology with vvi-miR3637-5p and gra-miR7484n. These homologous miRNAs seem to be encoded by pre-miRNA sequences located also at intronic regions (see Figure S9). No target genes were identified for any of the predicted miRNAs.

\section{Selection of Reference Genes}

The analysis of expression stability was performed with the following candidate reference genes: glyceraldehyde-3-phosphate dehydrogenase A subunit (GAPA), 18S (18SrRNA) and 26S (26SrRNA) ribosomal RNAs, beta-tubulin (TUB), ribulose1,5-bisphosphate carboxylase/oxygenase large subunit $(R B C L)$, glutamate-1-semialdehyde 2,1-aminomutase (GSA), chamba phenolic oxidative coupling protein (HYP1), and histone 2A (H2A). This analysis was performed to select the most suitable ones to be used to normalize the expression levels of target genes. GeNorm algorithm selected HpHYP1 and HpH2A $(M=0.347)$ simultaneously as the most stable genes (Figure S10A) with no need to include a third RG for normalization (Figure S10B). $H Y P 1$ is involved in plant defense and $H 2 A$ participates in nucleosome assembly.

TABLE 2 | Computational prediction of intronic miRNA precursors in AOX genes of Hypericum perforatum determined at miR-abela software (http://www.mirz.unibas.ch/cgi/pred_miRNA_genes.cgi) using as prediction threshold-10.

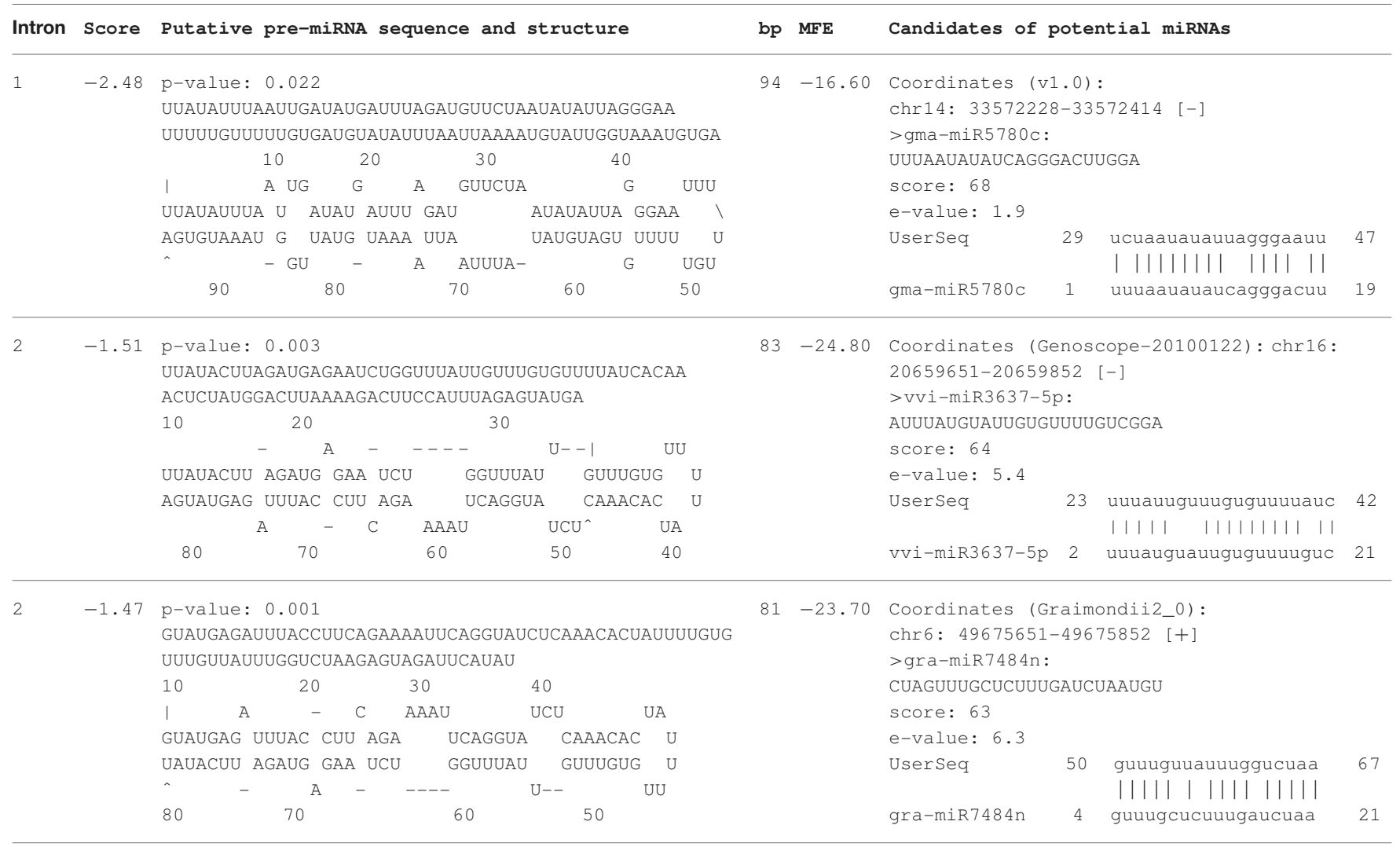

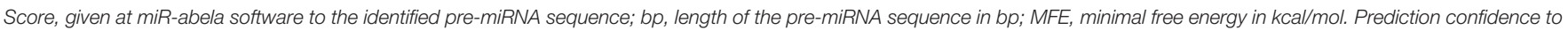

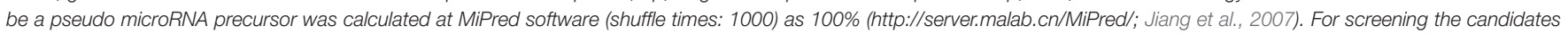
of potential miRNAs the validated pre-miRNA were run in the software miRBase (http://www.mirbase.org/search.shtml). 
The amplification specificity for each gene was confirmed by the melting curve analysis, observing amplification of the expected specific product and no formation of primer dimers (Figure S11). The slope and correlation coefficient $\left(r^{2}\right)$ values were given by the $\mathrm{AB}$ software. The $r^{2}$ ranged from 0.990 to 0.999 and the slope values ranged between -3.780 (PCR efficiency $=83.9 \%$ ) for HPGAPA and -3.347 (PCR efficiency $=98.9 \%$ ) for $H p R B C L$ (Table $\mathbf{1}$ ). The PCR efficiency for HPGAPA revealed to be low, nevertheless, and due to the fact the corresponding $r^{2}$ was high (0.999), the gene was not discarded from the analysis. The PCR efficiency value for HpGAPA was taken into account in the formula for the RQ calculation.

\section{Analysis of Transcript Expression}

The transcript expression profiles of HpAOX1, HpAOX2, HpCAT1, and also HPGAPA were analyzed in the present work. The amplification specificity of the genes was verified by the melting curve analysis (Figure S11). The geometric mean of the 2 top-ranked RGs (HpHYP1 and HpH2A), given by the GeNorm algorithm, was used in gene expression data normalization, as described above in the "Selection of reference genes" section.

The mRNA of HpAOX1 was maintained constant from day 4 after seed in vitro sowing (dps, days post-sowing) up to day 8 , nevertheless, after this time point, an accumulation of the transcript was observed up to $14 \mathrm{dps}$ with an increase of approximately 10 -fold ( $p \leq 0.05$; Figure $4 \mathrm{~A}$ ). The mRNA expression of HpAOX2 did not differ statistically over time in the post-germination process, even if a slight tendency to decrease (1.8-fold-change) from day 4 to 6 after seeds sowing was observed. This expression was maintained up to day 10 post-sowing and a subsequent complete recovery was observed up to day 14 , demonstrating high stability of this gene during the developmental process (Figure 4B). The expression of HPCAT1 transcript showed a gradual down-regulation over the $12 \mathrm{dps}$ of about 3.8 -fold $(p \leq 0.05)$ which was maintained up to $14 \mathrm{dps}$ (Figure 4C). The HpGAPA transcript increased drastically about 64 -fold $(p \leq 0.01)$ from day 4 up to day 12, maintaining the expression at elevated levels up to day 14 (Figure 4D).

\section{DISCUSSION}

\section{HpAOX Genes Sequence Analysis}

Mitochondrial AOX proteins are encoded by a small nuclear gene family, with a maximum of six gene members (Cardoso et al., 2015) distributed in 2 subfamilies, AOX1 and AOX2 (Considine et al., 2002; Borecky et al., 2006). In higher plants $A O X 1$ is found in all studied monocot and eudicot plant species while AOX2 is only present in eudicots (Considine et al., 2002). The number of $A O X$ gene members and its pattern of expansion is highly variable across eudicot plant species (Cardoso et al., 2015). At genome level, $A O X$ genes appear usually as single copy genes. Nevertheless, 17 cases of duplication events can also be seen in different plant species. The majority of these duplicated copies are adjacent to the original (tandem repeats, e.g., SapurV1A.0377s0140.1.p and SapurV1A. 0377s0150.1.p). Three exceptions appear with the duplicated sequence located somewhere along the chromosome (e.g., SapurV1A.1470s0080.1 and SapurV1A.0346s0170.1). Tandem duplication events have been described as one of the major mechanisms that creates new genes, particularly in cases where genes are clustered into a gene family (Fan et al., 2008). In $H$. perforatum it was identified the complete sequence of two AOX genes, one belonging to the AOX1-subfamily and the other to the $A O X 2$-subfamily. Considering the efforts made to isolate the complete sequence of all the previous reported $H p A O X$ genes (Ferreira et al., 2009) it is here hypothesized that the $A O X$ gene family in $H$. perforatum is composed by only two gene members.

Alternative oxidase is a diiron carboxylate protein composed by two monomers (dimeric protein). Each monomer is composed by six long helices ( $\alpha 1$ to $\alpha 6$ ) and four short helices ( $\alpha \mathrm{S} 1$ to $\alpha \mathrm{S} 4$ ) arranged in an antiparallel fashion. Helices $\alpha 2, \alpha 3, \alpha 5$, and $\alpha 6$ forming a four-helix bundle (Moore et al., 2013) accommodate the active site composed by the diiron center, four universally conserved glutamate residues, and two universally conserved histidine residues. The alignment made across deduced AOX sequences, including both HpAOX sequences, shows not only the high conservation on the regions of the long helices, but also the complete conservation of the four glutamate (Glu-201, Glu240, Glu-291, and Glu-342) and the two histidine (His-243 and His-345) residues.

Nevertheless, an exception can be seen at the HpAOX2 sequence where the Ile-230 is substituted by a Val. This position corresponds to the Ile-207 in Sauromatum guttatum and to the Ile-152 in Trypanosoma brucei previously investigated by mutagenesis approach (see review at Moore et al., 2013). In an attempt to elucidate about the occurrence of this change, an alignment was constructed including high number of AOX sequences available at different Gene Banks (not shown). This allowed the identification of the same amino acid change in a sequence of $V$. vinifera (acc. VV00G00110). Nevertheless, no data are available about the effect of this mutation on the inhibition of respiration.

Besides the effect that those changes at gene sequence level could have on protein functionality (see review at Moore et al. (2013), post-transcriptional events have also a role on $A O X$ regulation. In plants, $A O X$ is controlled at post-transcriptional level by two interrelated mechanisms, being one of them dependent of $\alpha$-keto acid regulation in which two cysteine residues are involved, CysI-145 and CysII-195 (Umbach et al., 2002), both conserved in HpAOX sequences. Nevertheless, some plant AOX lack the conserved CysI, having a SerI residue instead (Umbach and Siedow, 1993; Costa et al., 2009) which change the regulation from pyruvate to succinate (Holtzapffel et al., 2003; Grant et al., 2009). Recently, Moore et al. (2013) suggested that $A O X$ regulation might also occur via phosphorylation of the $\mathrm{N}$-terminal extension through charge-induced conformational changes and/or an interaction with other mitochondrial proteins. AOX N-terminal region is known as the less conserved region at size and sequence level, with the exception of the CysI, and has been considered independently from the structural defined 

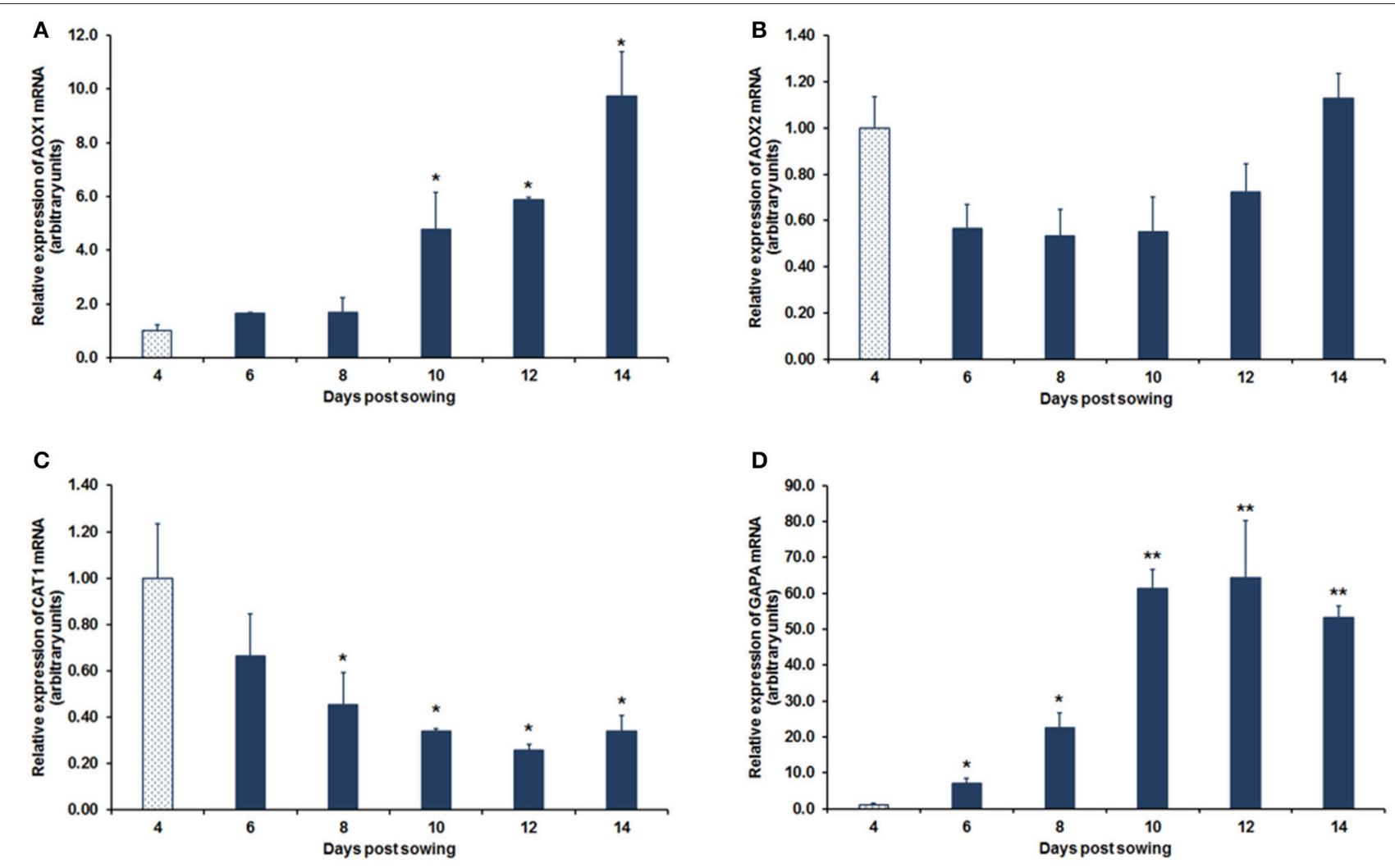

FIGURE 4 | Relative mRNA expression during post-germinative development of $\boldsymbol{H}$. perforatum seedlings. Transcript expression of $H p A O X 1$ (A), $H p A O X 2$ (B), HpCAT1 (C), and HpGAPA (D). HpHYP1 and HpH2A were used as reference genes in data normalization. The relative expression values are depicted as the mean \pm standard deviation of three biological replicates for each time point. The bars represent the fold-change related to the time point 4 days post-sowing, which was set to 1. Statistical significances $\left({ }^{\star} p \leq 0.05\right.$ and $\left.{ }^{* \star} p \leq 0.01\right)$ between the two means were determined by the $t$-test using IBM ${ }^{\circledR}$ SPSS ${ }^{\circledR}$ Statistics version 22.0 (SPSS Inc., USA).

four-helix bundle (Moore et al., 2013). The distance between CysI and CysII is 50 amino acids, as previously reported by Moore et al. (2013), but the distance between the predicted $\mathrm{N}$-terminal sequence and CysI varies. This variation can be explained by the variability at genomic level observed at the level of exon 1 since the other exons show a conservation in size across genes with the four exons structure (exon 2: 129, exon 3: 489, exon 4: 57 ). The prediction of the mitochondrial signal peptide located at $\mathrm{N}$-terminal region revealed no conservation at sequence and size level, going from very short mTP (AtAOX1b, acc. AT3G22360) to much longer (AtAOX2, acc. AT5G64210) although from the same plant species. This region determines the interaction of the peptide with the protein transport system to the organelle, and in many cases, amino acids comprising the signal peptide are cleaved off the protein once they reach their final destination. Finnegan et al. (1997) referred that proteins requiring $\mathrm{N}$-terminal signals for mitochondrial import typically present a lack in overall sequence conservation at the $\mathrm{N}$ terminus. Huang et al. (2009) also reported a high variability in this region in a comparison between Arabidopsis and rice using a high set of proteins, describing that this region varied greatly from 19 to 109 amino acids in Arabidopsis, and from 18 to 117 amino acids in rice. Specifically related with AOX, Campos et al. $(2009,2016)$ described length variability at the mTP across plant species and also between carrot protein isoforms. More recently, Nogales et al. (2016) reported the presence of single nucleotide polymorphisms (SNPs) within the mTP sequence in $A O X 1$ sequences across carrot genotypes.

The effect of those differences in the $\mathrm{N}$-terminal region for the regulation of gene expression, protein transport or activity is still unknown. Concerning the effect of the mTP sequence composition, structural studies revealed the importance of hydrophobic residues for mTP binding (Huang et al., 2009), and several studies on yeast, mammals, and plants revealed also that positively charged residues in $\mathrm{mTP}$ have a relevant role in protein import into mitochondria (Lister et al., 2005; Neupert and Herrmann, 2007). In plants, AOX are encoded by genes commonly composed by four exons interrupted by three size variable introns. Both $H p A O X$ genes present the four exons structure, with the three last exons showing size conservation. Nevertheless, events of intron loss and gain, responsible by the variability in gene structure and consequently in exons size variation, were previously reported in $A O X$ genes. A detailed description about $A O X$ gene structure variation can be found in different reports (Polidoros et al., 2009; Cardoso et al., 2015; Campos et al., 2016). 
In an attempt to search for putative motifs in $H p A O X$ genes that could be further used to develop molecular markers, the intronic regions were explored in silico. Previous reports pointed out the existence of intron length polymorphism at individual plant level in $H p A O X 1$, thus, pointing to the possibility for allelic discrimination (Ferreira et al., 2009). More recently Velada et al. (2014) pointed out the response of both $H p A O X$ genes upon temperature stress. These observations are highly promising for a perspective toward FM development. Sequence variability at intron level in $A O X$ genes has been suggested as a good source for functional polymorphisms that could be useful for FM development (Cardoso et al., 2009, 2011; Santos Macedo et al., 2009; Hedayati et al., 2015). In the present study, the identification of SSRs located at intronic regions of both $H p A O X$ genes makes them genes of interest for further search for variability among genotypes that could be used for FM development. Besides its abundance, SSRs are highly polymorphic compared with other genetic markers, as well as being species-specific and co-dominant. For these reasons, they have become increasingly important genetic markers ideal for detecting differences between and within species of genes of all eukaryotes (Farooq and Azam, 2002). Nevertheless, variation in the length of microsatellite motifs in protein non-coding gene sequences (i.e., promoters, UTRs, and introns) may affect the process of transcription and translation through slippage, gene silencing and pre-mRNA splicing as has been observed for many human disorders (e.g., Kim et al., 2001), and also in some plant species (Tan and Zhang, 2001; Bao et al., 2006; Wang et al., 2011). Therefore, SSR markers generated from those sequence motifs can be of great use in terms of FM selection for genomic studies and crop breeding applications (Parida et al., 2009). However, the development of SSR markers located in potentially functional genic sequences in plants has been scarce, and the unique example known is in Eucalyptus globules for wood quality traits (Acuña et al., 2012). The identification of SSRs within AOX gene sequences was firstly reported by Nogales et al. (2016) with the recognition of TTCTT tandem repeats in intron 1 of carrot AOX1 gene.

The increasing knowledge on the involvement of introns in the regulation of gene expression (Rose et al., 2008; Goebels et al., 2013; Heyn et al., 2015), particularly the encoding of important regulatory elements, makes introns of great interest for the identification of polymorphisms that can be responsible for phenotypical differences. MicroRNAs are an example of regulatory elements that can be encoded at intronic regions, playing its control by negatively regulating gene expression at post-transcriptional level. In plants, miRNAs play a critical role in almost all biological and metabolic processes, including plant development (Chen et al., 2015) and plant stress response (Bej and Basak, 2014). The identification of homologous miRNAs in distinct plant species is facilitated since many families of miRNAs are evolutionarily conserved across all principal lineages of plants (Axtell and Bartel, 2005; Zhang et al., 2006). Considering this knowledge, putative locations coding for precursors of miRNAs were identified at intronic regions of both $H p A O X$ genes. In all cases, a high homology with previously described miRNAs was found.
In the same way, also transposable elements (TE), which includes intact TEs, degenerate TEs and sequence residues of mobile elements (TE remnants), can also influence the regulation of gene expression (McDonald, 1993; Brosius, 2000; Bowen and McDonald, 2001; Ganko et al., 2001; Nekrutenko and Li, 2001), which leads to a significant effect in functional genome diversity and phenotypic variations (Yadav et al., 2015). The in silico analysis searching for TEs allowed us to identify a $119 \mathrm{bp}$ sequence in intron 1 of $H p A O X 2$ gene that showed similarity to the long terminal repeat region of a LTR retrotransposon (Cassandra MT-LTR) from Medicago truncatula. Whether this LTR remnant has any role in the regulation of $A O X$ expression still needs to be elucidated, but the fact that several TEs and their evolved sequences are highly polymorphic in sequence and in genome location facilitates development of TE-based markers for various genotyping purposes.

\section{Analysis of Transcript Expression}

The germination process involves many metabolic activities including a marked development of the photosynthetic and respiratory metabolisms. Thus, it is expected that AOX, like other antioxidative enzymes, would be involved in the process of seed germination and seedling development by the control of ROS produced during the germination process, and also in the promotion of the cellular homeostasis under the large metabolic changes that take place during germination and postgermination development.

To the best of our knowledge, this is the first report on the involvement of $A O X$ genes in the post-germinative development of seedlings in $H$. perforatum. In the present study, a high increase for HpAOX1 transcript was observed from 8 dps on. On the contrary, HpAOX2 showed less variation in the expression of its transcript even if a slight tendency to decrease was observed right from day 4 . These results are in agreement with other studies showing, for example, a decrease in the relative abundance of $A O X 2$ transcripts during seedling development in soybean, whereas the transcripts of the other $A O X$ genes increased (McCabe et al., 1998). Other example are the findings from Saisho et al. (2001) demonstrating that the expression of AOX2 in Arabidopsis was high in dry seeds and subsequently decreased during early germination, whereas AOX1a was less abundant at the beginning of the process, increasing only in a later stage. Several examples illustrate, as well, the involvement of $A O X$ on plant vegetative growth and reproductive performance. In general, $A O X 1$ sub-family members are reported as more responsive genes upon stress factors, whereas $A O X 2$ members were considered during years not being affected by stress conditions, being more involved in developmental and growth processes events (Considine et al., 2002; Chai et al., 2012). Nevertheless, further studies have showed that AOX2 members are also involved in plastid-dependent signaling (Clifton et al., 2005) and in plant stress response (Costa et al., 2010; Campos et al., 2016).

Interestingly, the increment in HpAOX1 mRNA levels was accompanied by also a marked increase of the chloroplast HPGAPA transcript, having both transcripts a similar expression pattern during the post-germinative process of seedlings. 
HPGAPA was first used in our study in the expression stability analysis to select the most suitable RGs because it is commonly used as reference gene in data normalization of RT-qPCR studies, and particularly in studies involving gene expression during growth and development of seedlings, like in Zea mays (Sytykiewicz, 2014), Arabidopsis thaliana (Rigas et al., 2009), Oryza sativa (Ismail et al., 2009), or Triticum sp. (Boutrot et al., 2005). However, in our study, HPGAPA showed to be the most unstable gene among all tested candidate reference genes, and therefore, it seems not to be appropriate to be used as RG in the experimental conditions of the present study. Our findings are in accordance with other recent studies demonstrating also the unsuitability of this gene for data normalization purposes involving gene expression in seedlings, such as in Sasha inchi (Niu et al., 2015), or in Oryza sativa (Moraes et al., 2015). The gene product of GAPA is a key enzyme in the photosynthetic carbon fixation pathway (Cerff, 1982), and therefore, the marked increase of its transcript observed in our study might indicate an increment of the photosynthetic activity during the postgerminative process. In fact, green tissues started to be more apparent at that time (Figure 1). Dewdney et al. (1993) found that the expression of the GAPA gene is regulated by light in Arabidopsis seedlings. In the same line, other works showed that the increase of total photosynthetic activity was accompanied by an increase in the GAPDH activity in response to light (Shih and Goodman, 1988 and references therein).

Taken together, it could be hypothesized that the increment in GAPA gene expression, and possibly in the photosynthetic activity, is closely related to an increased need of the HPAOX1 enzyme during the post-germinative process of $H$. perforatum. This would be in accordance with previous reports about the role of AOX in optimizing photosynthesis (Dinakar et al., 2016). Indeed, it has been reported that AOX has a role in optimizing photosynthesis, e.g., by maintaining a balanced carbon and energy metabolisms (Watanabe et al., 2008), by keeping up the light activation of chloroplastic enzymes (Padmasree and Raghavendra, 2001), by functioning as a sink for the excess reducing equivalents generated by photosynthesis (Yoshida et al., 2006, 2007), or by regulating ROS levels (Dinakar et al., 2016). With regard to the latter, during active photosynthesis there are four major types of ROS being produced in green tissues, such as, singlet oxygen $\left(\mathrm{O}_{2}\right)$, superoxide $\left(\mathrm{O}_{2}^{-}\right)$, hydrogen peroxide $\left(\mathrm{H}_{2} \mathrm{O}_{2}\right)$, and hydroxyl radicals $\left(\mathrm{OH}^{-}\right)$(Apel and Hirt, 2004). AOX has been described as a potential means to dampen $\mathrm{O}_{2}^{-}$ production by the ETC (Purvis and Shewfelt, 1993) and catalase, other antioxidative enzyme also analyzed in our study, as having a role in the hydrogen peroxide scavenging (Puntarulo et al., 1988; Møller, 2001; Mittler, 2002; Dinakar et al., 2010).

Unlike $H p A O X 1$ and $H p G A P A, H p C A T 1$ revealed a gradual down-regulation in its transcript levels reaching the peak of down-regulation at $12 \mathrm{dps}$, which suggests an involvement of HPCAT1 during the post-germinative process in $\mathrm{H}$. perforatum. Several studies imply that CAT activity is necessary for seed germination and early seedling growth and its measurement may be used as a parameter to examine seed viability and germination (Ak et al., 2012 and references therein). Indeed, most of these works revealed higher levels of catalase activity related to germination, whereas our data revealed a down-regulated expression for this gene. It should not rule out the possibility that other catalase isoforms may be present in this process, having a different behavior. However, they were not included in this study since no information about their nucleotide sequence are available in databases. Additionally, it must be noticed that in our study the germination process has already finished at the first time point considered ( $4 \mathrm{dps})$, since the radicle emerging from the seed coat was already observable. The subsequent steps consisted in the post-germinative process with the development of seedlings. Therefore, it would be plausible that the peak observed on HpCAT1 expression might have occurred earlier during the first stages of $H$. perforatum seeds germination (before $4 \mathrm{dps}$ ), when HPCAT1 is more required, and that the subsequent decrease on transcript accumulation that we observed might be related to the necessity of maintaining ROS at adequate levels for cellular survival. Indeed, it has been reported that excessive removal of hydrogen peroxide free radicals might reduce the inhibition of the cellular cycle, which is important for DNA repair (Santos et al., 2013). In the same line, cellular biology studies have clearly described the beneficial functions of hydrogen peroxide to the cell, beyond causing oxidative stress. One of these beneficial functions is stopping the cellular cycle during DNA repair after certain types of stress and aging (Santos et al., 2013). Accordingly to our results, Mhamdi et al. (2012) reported that a transcriptional down-regulation of CAT could be important to induce or sustain increased $\mathrm{H}_{2} \mathrm{O}_{2}$ availability necessary for certain environmental responses or developmental processes.

Taken together, we suggest that fluctuations in the expression between $H p A O X 1$ and HpCAT1 might occur in order to control ROS levels during the germination process in H. perforatum.

In summary, to the best of our knowledge, this is the first study in which the characterization of the $A O X$ gene family is reported in $H$. perforatum and the expression of their transcripts are analyzed during the post-germinative development of seedlings. Two HpAOX genes were identified, one belonging to the $A O X 1$-subfamily and another to the AOX2-subfamily. Sequence variability was observed at $3^{\prime}$ and $5^{\prime}$ ends. At the $\mathrm{N}$-terminal region, the variability was reported across $A O X$ gene members within a species and among species. Besides, SSR, a TE remnant and putative miRNA coding sequences were detected in intronic regions of $H p A O X$ genes, whose variability could be explored across genotypes to identify polymorphisms with functional significance that would allow functional marker development. Our findings, although preliminary, lead us to consider $H p A O X$ members, in particular $H p A O X 1$, as relevant to investigate further, also at the protein level (e.g., amount, activity and capacity), in post-germinative processes in order to explore its role in optimizing photosynthesis and in the control of ROS levels. This would help making the link between gene function and the desired phenotype related to better germination rates and consequently to develop a functional marker for it.

\section{AUTHOR CONTRIBUTIONS}

$\mathrm{HC}$ contributed to the conception and design of the work; to the acquisition, analysis, and interpretation of data; to the drafting and critical revision of the work; and to the final approval of the manuscript; IV contributed to the acquisition, analysis, and 
interpretation of data; to the drafting and critical revision of the work, and to the final approval of the manuscript; CR contributed to the conception and design of the work; to the acquisition of data; to the drafting and revision of the work; and to the final approval of the manuscript; AN contributed to the analysis and interpretation of data; to the drafting and critical revision of the work; and to the final approval of the manuscript; AF contributed to the conception and design of the work; to the acquisition of data; to the drafting of the work and to the final approval of the manuscript; VV contributed to the acquisition of data; to the drafting of the work; and to the final approval of the manuscript; BA contributed to the interpretation of data; to the critical revision of the work; and to the final approval of the manuscript. All authors are responsible for all the work.

\section{FUNDING}

This work was funded by the European Commission (MEXC-CT2004-006669) through providing the EU Marie Curie Chair and by the National Funds through FCT - Foundation for Science and Technology under the Project UID/AGR/00115/2013, and

\section{REFERENCES}

Acuña, C. V., Villalba, P. V., García, M., Pathauer, P., Hopp, H. E., and Marcucci Poltri, S. N. (2012). Microsatellite markers in candidate genes for wood properties and its application in functional diversity assessment in eucalyptus globules. Electron. J. Biotechnol. 15, 1-17. doi: 10.2225/vol15-issue2-fulltext-3

Ak, A., Yücel, E., and Ayan, S. (2012). Relationship between seed germination and catalase enzyme activity of abies taxa from Turkey. J. For. Fac. 12, 185-188. doi: 10.17475/kuofd.74547

Amirsadeghi, S., Robson, C., and Vanlerberghe, G. C. (2007). The role of the mitochondrion in plant responses to biotic stress. Physiol. Plant. 129, 253-266. doi: 10.1111/j.1399-3054.2006.00775.x

Andersen, J. R., and Lübberstedt, T. (2003). Functional markers in plants. Trends Plant Sci. 8, 554-560. doi: 10.1016/j.tplants.2003.09.010

Apel, K., and Hirt, H. (2004). Reactive oxygen species: metabolism, oxidative stress, and signal transduction. Annu. Rev. Plant Biol. 55, 373-399. doi: 10.1146/annurev.arplant.55.031903.141701

Arnholdt-Schmitt, B. (2005). Efficient cell reprogramming as a target for functional marker strategies? Towards new perspectives in applied plant nutrition research. J. Plant Nutr. Soil. Sci. 168, 617-624. doi: 10.1002/jpln.2004 20493

Arnholdt-Schmitt, B., Costa, J. H., and Fernandes de Melo, D. (2006). AOX - a functional marker for efficient cell reprogramming under stress? Trends Plant Sci. 11, 281-287. doi: 10.1016/j.tplants.2006.05.001

Axtell, M. J., and Bartel, D. P. (2005). Antiquity of microRNAs and their targets in land plants. Plant Cell 17, 1658-1673. doi: 10.1105/tpc.105.032185

Bailly, C., El-Maarouf-Bouteau, H., and Corbineau, F. (2008). From intracellular signaling networks to cell death: the dual role of reactive oxygen species in seed physiology. C. R. Biol. 331, 806-814. doi: 10.1016/j.crvi.2008.07.022

Bao, J. S., Corke, H., and Sun, M. (2006). Microsatellite, single nucleotide polymorphisms and a sequence tagged site in starch-synthesizing genes in relation to starch physicochemical properties in nonwaxy rice (Oryza sativa L.). Theor. Appl. Genet. 113, 1185-1196. doi: 10.1007/s00122-006-0394-z

Bej, S., and Basak, J. (2014). MicroRNAs: the potential biomarkers in plant stress response. Am. J. Plant Sci. 5, 748-759. doi: 10.4236/ajps.2014.55089

Bimboim, H. C., and Doly, J. (1979). A rapid alkaline extraction procedure for screening recombinant plasmid DNA. Nucleic Acids Res. 7, 1513-1523. doi: $10.1093 /$ nar/7.6.1513 under the project PTDC/AGRGPL/099263/2008. The authors are also thankful to FCT for the support provided under the program POPH-Programa Operacional Potencial Humano to BA and HC (Ciência 2007 and Ciência 2008: C2008-UE/ICAM/06), and also to ICAAM and UEvora for the support given to HC (BPD UEvora ICAAM INCENTIVO AGR UI0115 and BI_PosDoc_UEVORA_Calorespirometria_2).

\section{ACKNOWLEDGMENTS}

The authors are very grateful to Tânia Nobre for valuable suggestions and the help on the AOX phylogenetic analysis. The authors especially thank Dariusz Grzebelus for great help in the analysis of $A O X$ sequences to search for SSR and TE elements. The authors also thank to Virginia Sobral for technical assistance.

\section{SUPPLEMENTARY MATERIAL}

The Supplementary Material for this article can be found online at: http://journal.frontiersin.org/article/10.3389/fpls.2016. 01043

Borecky, J., Nogueira, F. T., de Oliveira, K. A., Maia, I. G., Vercesi, A. E., and Arruda, P. (2006). The plant energy-dissipating mitochondrial systems: depicting the genomic structure and the expression profiles of the gene families of uncoupling protein and alternative oxidase in monocots and dicots. J. Exp. Bot. 57, 849-864. doi: 10.1093/jxb/erj070

Botha, F. C., Potgieter, G. P., and Botha, A. M. (1992). Respiratory metabolism and gene expression during seed germination. Plant Growth Regul. 11, 211-224. doi: 10.1007/BF00024560

Boutrot, F., Guirao, A., Alary, R., Joudrier, P., and Gautier, M.-F. (2005). Wheat non-specific lipid transfer protein genes display a complex pattern of expression in developing seeds. Biochim. Biophys. Acta 1730, 114-125. doi: 10.1016/j.bbaexp.2005.06.010

Bowen, N. J., and McDonald, J. F. (2001). Drosophila euchromatic LTR retrotransposons are much younger than the host species in which they reside. Genome Res. 11, 1527-1540. doi: 10.1101/gr.164201

Brosius, J. (2000). "Genomes were forged by massive bombardments with retroelements and retrosequences," in Transposable Elements and Genome Evolution, ed J. F. McDonald (Dordrecht: Kluwer Academic Publishers), 209-238.

Campos, M. D., Cardoso, H. G., Linke, B., Costa, J. H., Fernandes de Melo, D., Justo, L., et al. (2009). Differential expression and coregulation of carrot AOX genes (Daucus carota L.). Physiol. Plant. 137, 578-591. doi: 10.1111/j.13993054.2009.01282.x

Campos, M. D., Nogales, A., Cardoso, H. G., Sarma, R. K., Nobre, T., Sathishkumar, R., et al. (2016). Stress-induced accumulation of DcAOX1 and DcAOX2a transcripts coincides with critical time point for structural biomass prediction in carrot primary cultures (Daucus carota L.). Front. Genet. 7:1. doi: 10.3389/fgene.2016.00001

Cardoso, H., Campos, M. D., Nothnagel, T., and Arnholdt-Schmitt, B. (2011). Polymorphisms in intron 1 of carrot AOX2b - a useful tool to develop a functional marker? Plant Genet. Resour. C. 9, 177-180. doi: $10.1017 /$ S1479262111000591

Cardoso, H. G., and Arnholdt-Schmitt, B. (2013). "Functional marker development across species in selected traits" in Diagnostics in Plant Breeding, eds T. Lübberstedt and R. K. Varshney (Dordrecht: Springer), 467-515.

Cardoso, H. G., Campos, M. D., Costa, A. R., Campos, M. C., Nothnagel, T., and Arnholdt-Schmitt, B. (2009). Carrot alternative oxidase 
gene AOX2a demonstrates allelic and genotypic polymorphisms in intron 3. Physiol. Plant. 137, 592-608. doi: 10.1111/j.1399-3054.2009. 01299.x

Cardoso, H. G., Nogales, A., Frederico, A. M., Svensson, J. T., Santos Macedo, E., Valadas, V., et al. (2015). "Natural AOX gene diversity" in Alternative Respiratory Pathways in Higher Plants, eds K. J. Gupta, L. A. J. Mur, and B. Neelwarne (Chichester, UK: John Wiley \& Sons Inc, Oxford), 241-254.

Cerff, R. (1982). "Separation and purification of NAD- and NADP linked glyceraldehyde-3-phosphate dehydrogenases from higher plants," in Methods in Chloroplast Molecular Biology, eds N. -H. C. M. Edelman and R. B. Hallick (Amsterdam: Elsevier-North Holland), 683-694.

Chai, T. T., Simmonds, D., Day, D. A., Colmer, T. D., and Finnegan, P. M. (2012). A GmAOX2b antisense gene compromises vegetative growth and seed production in soybean. Planta 236, 199-207. doi: 10.1007/s00425-012-1601-6

Chen, Y., Gao, D. Y., and Huang, L. (2015). In vivo delivery of miRNAs for cancer therapy: challenges and strategies. Adv. Drug Deliv. Rev. 81, 128-141. doi: 10.1016/j.addr.2014.05.009

Clifton, R., Lister, R., Parker, K. L., Sappl, P. G., Elhafez, D., Millar, A. H., et al. (2005). Stress-induced co-expression of alternative respiratory chain components in Arabidopsis thaliana. Plant Mol. Biol. 58, 193-212. doi: 10.1007/s11103-005-5514-7

Clifton, R., Millar, A. H., and Whelan, J. (2006). Alternative oxidases in Arabidopsis: a comparative analysis of differential expression in the gene family provides new insights into function of non-phosphorylating bypasses. Biochim. Biophys. Acta 1757, 730-741. doi: 10.1016/j.bbabio.2006.03.009

Collins, N. C., Tardieu, F., and Tuberosa, R. (2008). Quantitative trait loci and crop performance under abiotic stress: where do we stand? Plant Physiol. 147, 469-486. doi: 10.1104/pp.108.118117

Considine, M. J., Holtzapffel, R. C., Day, D. A., Whelan, J., and Millar, A. H. (2002). Molecular distinction between alternative oxidase from monocots and dicots. Plant Physiol. 129, 949-953. doi: 10.1104/pp.004150

Costa, J. H., Fernandes de Melo, D., Gouveia, Z., Cardoso, H. G., Peixe, A., and Arnholdt-Schmitt, B. (2009). The alternative oxidase family of Vitis vinifera reveals an attractive model to study the importance of genomic design. Physiol. Plant. 137, 553-565. doi: 10.1111/j.1399-3054.2009.01267.x

Costa, J. H., Mota, E. F., Cambursano, M. V., Lauxmann, M. A., de Oliveira, L. M. N., Silva Lima Mda, G., et al. (2010). Stress-induced co-expression of two alternative oxidase (VuAox1 and 2b) genes in Vigna unguiculata. J. Plant Physiol. 167, 561-570. doi: 10.1016/j.jplph.2009.11.001

Dewdney, J., Conley, T. R., Shih, M. C., and Goodman, H. M. (1993). Effects of blue and red light on expression of nuclear genes encoding chloroplast glyceraldehyde-3-phosphate dehydrogenase of Arabidopsis thaliana. Plant Physiol. 103, 1115-1121. doi: 10.1104/pp.103.4.1115

Dinakar, C., Abhaypratap, V., Yearla, S. R., Raghavendra, A. S., and Padmasree, K. (2010). Importance of ROS and antioxidant system during the beneficial interactions of mitochondrial metabolism with photosynthetic carbon assimilation. Planta 231, 461-474. doi: 10.1007/s00425-009-1067-3

Dinakar, C., Vishwakarma, A., Raghavendra, A. S., and Padmasree, K. (2016). Alternative oxidase pathway optimizes photosynthesis during osmotic and temperature stress by regulating cellular ROS, malate valve and antioxidative systems. Front. Plant Sci. 7:68. doi: 10.3389/fpls.2016.00068

Emanuelsson, O., Nielsen, H., Brunak, S., and von Heijne, G. (2000). Predicting subcellular localization of proteins based on their $\mathrm{N}$-terminal amino acid sequence. J. Mol. Biol. 300, 1005-1016. doi: 10.1006/jmbi.2000.3903

Esashi, Y., Sakai, Y., and Ushizawa, R. (1981). Cyanide-sensitive and cyanideresistant respiration in the germination of cocklebur seeds. Plant Physiol. 67, 503-508. doi: 10.1104/pp.67.3.503

Fan, C., Chen, Y., and Long, M. (2008). Recurrent tandem gene duplication gave rise to functionally divergent genes in Drosophila. Mol. Biol. Evol. 25, 1451-1458. doi: 10.1093/molbev/msn089

Farooq, S., and Azam, F. (2002). Molecular markers in plant breedingI: concepts and characterization. Pak. J. Biol. Sci. 5, 1135-1140. doi: 10.3923/pjbs.2002.1135.1140

Ferreira, A. O., Cardoso, H. G., Macedo, E. S., Breviario, D., and ArnholdtSchmitt, B. (2009). Intron polymorphism pattern in AOX1b of wild St John's wort (Hypericum perforatum) allows discrimination between individual plants. Physiol. Plant. 137, 520-531. doi: 10.1111/j.1399-3054.2009. 01291.x
Finnegan, P. M., Whelan, J., Millar, A. H., Zhang, Q., Smith, M. K., Wiskich, J. T., et al. (1997). Differential expression of the multigene family encoding the soybean mitochondrial alternative oxidase. Plant Physiol. 114, 455-466. doi: 10.1104/pp.114.2.455

Frederico, A. M., Campos, M. D., Cardoso, H. G., Imani, J., and ArnholdtSchmitt, B. (2009). Alternative oxidase involvement in Daucus carota somatic embryogenesis. Physiol. Plant. 137, 498-508. doi: 10.1111/j.13993054.2009.01278.x

Ganko, E. W., Fielman, K. T., and McDonald, J. F. (2001). Evolutionary history of cer elements and their impact on the C. elegans genome. Genome Res. 11, 2066-2074. doi: 10.1101/gr.196201

Gartner, M., Müller, T., Simon, J. C., Giannis, A., and Sleeman, J. P. (2005). Aristoforin, a novel stable derivative of hyperforin, is a potent anticancer agent. Chembiochem 6, 171-177. doi: 10.1002/cbic.200400195

Goebels, C., Thonn, A., Gonzalez-Hilarion, S., Rolland, O., Moyrand, F., Beilharz, T. H., et al. (2013). Introns regulate gene expression in Cryptococcus neoformans in a Pab2p dependent pathway. PLoS Genet. 9:e1003686. doi: 10.1371/journal.pgen.1003686

Grant, N., Onda, Y., Kakizaki, Y., Ito, K., Watling, J., and Robinson, S. (2009). Two cys or not two cys? That is the question; alternative oxidase in the thermogenic plant sacred lotus. Plant Physiol. 150, 987-995. doi: 10.1104/pp.109. 139394

Hedayati, V., Mousavi, A., Razavi, K., Cultrera, N., Alagna, F., Mariotti, R., et al. (2015). Polymorphisms in the AOX2 gene are associated with the rooting ability of olive cuttings. Plant Cell Rep. 34, 1151-1164. doi: 10.1007/s00299-015$1774-0$

Heyn, P., Kalinka, A. T., Tomancak, P., and Neugebauer, K. M. (2015). Introns and gene expression: cellular constraints, transcriptional regulation, and evolutionary consequences. Bioessays 37, 148-154. doi: 10.1002/bies.201400138

Holtzapffel, R. C., Castelli, J., Finnegan, P. M., Millar, A. H., Whelan, J., and Day, D. A. (2003). A tomato alternative oxidase protein with altered regulatory properties. Biochim. Biophys. Acta 1606, 153-162. doi: 10.1016/S00052728(03)00112-9

Huang, S., Taylor, N. L., Whelan, J., and Millar, A. H. (2009). Refining the definition of plant mitochondrial presequences through analysis of sorting signals, $\mathrm{N}$ terminal modifications, and cleavage motifs. Plant Physiol. 150, 1272-1285. doi: 10.1104/pp.109.137885

Ismail, A. M., Ella, E. S., Vergara, G. V., and Mackill, D. J. (2009). Mechanisms associated with tolerance to flooding during germination and early seedling growth in rice (Oryza sativa). Ann. Bot. 103, 197-209. doi: 10.1093/aob/mcn211

Jiang, P., Wu, H., Wang, W., Ma, W., Sun, X., and Lu, Z. (2007). MiPred classification of real and pseudo microRNA precursors using random forest prediction model with combined features. Nucleic Acids Res. 35, 339-344. doi: 10.1093/nar/gkm368

Karlin, S., and Altschul, S. F. (1993). Applications and statistics for multiple highscoring segments in molecular sequences. Proc. Natl. Acad. Sci. U.S.A. 90, 5873-5877. doi: 10.1073/pnas.90.12.5873

Kim, G. P., Colangelo, L., Allegra, C., Glebov, O., Parr, A., Hooper, S., et al. (2001). Prognostic role of microsatellite instability in colon cancer. Proc. Am. Soc. Clin. Oncol. 20:1666.

Kohany, O., Gentles, A. J., Hankus, L., and Jurka, J. (2006). Annotation, submission and screening of repetitive elements in Repbase: RepbaseSubmitter and Censor. BMC Bioinformatics 7:474. doi: 10.1186/1471-2105-7-474

Kubin, A., Wierrani, F., Burner, U., Alth, G., and Grunberger, W. (2005). Hypericin-the facts about a controversial agent. Curr. Pharm. Des. 11, 233-253. doi: $10.2174 / 1381612053382287$

Kwak, J. M., Nguyen, V., and Schoeder, J. I. (2006). The role of reactive oxygen species in hormonal responses. Plant Physiol. 141, 323-329. doi: 10.1104/pp.106.079004

Lister, R., Hulett, J. M., Lithgow, T., and Whelan, J. (2005). Protein import into mitochondria: origins and functions today. Mol. Membr. Biol. 22, 87-100. doi: $10.1080 / 09687860500041247$

Maron, J. L., Elmendorf, S. C., and Vilà, M. (2007). Contrasting plant physiological adaptation to climate in the native and introduced range of Hypericum perforatum. Evolution 61, 1912-1924. doi: 10.1111/j.1558-5646.2007. 00153.x

Mathews, D. H., Sabina, J., Zuker, M., and Turner, D. H. (1999). Expanded sequence dependence of thermodynamic parameters improves 
prediction of RNA secondary structure. J. Mol. Biol. 288, 911-940. doi: 10.1006/jmbi.1999.2700

McCabe, T. C., Finnegan, P. M., Millar, A. H., Day, D. A., and Whelan, J. (1998). Differential expression of alternative oxidase genes in soybean cotyledons during postgerminative development. Plant Physiol. 118, 675-682. doi: $10.1104 /$ pp.118.2.675

McDonald, J. F. (1993). Evolution and consequences of transposable elements. Curr. Opin. Genet. Dev. 3, 855-864. doi: 10.1016/0959-437X(93) 90005-A

Mhamdi, A., Noctor, G., and Baker, A. (2012). Plant catalases: peroxisomal redox guardians. Arch. Biochem. Biophys. 525, 181-194. doi: 10.1016/j.abb.2012.04.015

Mhamdi, A., Queval, G., Chaouch, S., Vanderauwera, S., Van Breusegem, F., and Noctor, G. (2010). Catalase function in plants: a focus on Arabidopsis mutants as stress-mimic models. J. Exp. Bot. 61, 4197-4220. doi: 10.1093/jxb/ erq282

Mittler, R. (2002). Oxidative stress, antioxidants and stress tolerance. Trends Plant Sci. 7, 405-410. doi: 10.1016/S1360-1385(02)02312-9

Møller, I. M. (2001). Plant mitochondria and oxidative stress: electron transport, NADPH turnover, and metabolism of reactive oxygen species. Annu. Rev. Plant Biol. 52, 561-591. doi: 10.1146/annurev.arplant.52.1.561

Møller, I. M., Jensen, P. E., and Hansson, A. (2007). Oxidative modifications to cellular components in plants. Annu. Rev. Plant. Biol. 58, 459-481. doi: 10.1146/annurev.arplant.58.032806.103946

Moore, A. L., Shiba, T., Young, L., Harada, S., Kita, K., and Ito, K. (2013). Unraveling the heater-new insights into the structure of the alternative. Annu. Rev. Plant. Biol. 64, 637-663. doi: 10.1146/annurev-arplant-042811-105432

Moraes, G. P., Benitez, L. C., do Amaral, M. N., Vighi, I. L., Auler, P. A., da Maia, L. C., et al. (2015). Evaluation of reference genes for RT-qPCR studies in the leaves of rice seedlings under salt stress. Genet. Mol. Res. 14, 2384-2398. doi: 10.4238/2015.March.27.24

Neale, D. B., and Savolainen, O. (2004). Association genetics of complex traits in conifers. Trends Plant Sci. 9, 325-330. doi: 10.1016/j.tplants.2004.05.006

Nekrutenko, A., and Li, W. H. (2001). Transposable elements are found in a large number of human protein- coding genes. Trends Genet. 17, 619-621. doi: 10.1016/S0168-9525(01)02445-3

Neupert, W., and Herrmann, J. M. (2007). Translocation of proteins into mitochondria. Annu. Rev. Biochem. 76, 723-749. doi: 10.1146/annurev.biochem.76.052705.163409

Niu, L., Tao, Y.-B., Chen, M.-S., Fu, Q., Li, C., Dong, Y., et al. (2015). Selection of reliable reference genes for gene expression studies of a promising oilseed crop, Plukenetia volubilis, by real-time quantitative PCR. Int. J. Mol. Sci. 16, 12513-12530. doi: 10.3390/ijms160612513

Nogales, A., Nobre, T., Cardoso, H. G., Muñoz-Sanhueza, L., Valadas, V., Campos, M. D., et al. (2016). Allelic variation on DcAOX1 gene in carrot (Daucus carota L.): An interesting simple sequence repeat in a highly variable intron. Plant Gene 5, 49-55. doi: 10.1016/j.plgene.2015.11.001

Oracz, K., El-Maarouf-Bouteau, H., Kranner, I., Bogatek, R., Corbineau, F., and Bailly, C. (2009). The mechanisms involved in seed dormancy alleviation by hydrogen cyanide unravel the role of reactive oxygen species as key factors of cellular signaling during germination. Plant Physiol. 150, 494-505. doi: 10.1104/pp.109.138107

Padmasree, K., and Raghavendra, A. S. (2001). Restriction of mitochondrial oxidative metabolism leads to suppression of photosynthetic carbon assimilation but not of photochemical electron transport in pea mesophyll protoplasts. Curr. Sci. 81, 680-684.

Parida, S. K., Dalal, V., Singh, A. K., Singh, N. K., and Mohapatra, T. (2009). Genic non-coding microsatellites in the rice genome: characterization, marker design and use in assessing genetic and evolutionary relationships among domesticated groups. BMC Genomics 10:140. doi: 10.1186/1471-21 64-10-140

Pergo, É. M., and Ishii-Iwamoto, E. L. (2011). Changes in energy metabolism and antioxidant defense systems during seed germination of the weed species Ipomoea triloba L. and the responses to allelochemicals. J. Chemi. Ecol. 37, 500-513. doi: 10.1007/s10886-011-9945-0

Polidoros, A. N., Mylona, P. V., and Arnholdt-Schmitt, B. (2009). AOX gene structure, transcript variation and expression in plants. Physiol. Plant. 137, 342-353. doi: 10.1111/j.1399-3054.2009.01284.x
Popov, V., Simonian, R., Skulachev, V., and Starkov, A. (1997). Inhibition of the alternative oxidase stimulates $\mathrm{H} 2 \mathrm{O} 2$ production in plant mitochondria. FEBS Lett. 415, 87-90. doi: 10.1016/S0014-5793(97)01099-5

Puntarulo, S., Sánchez, R. A., and Boveris, A. (1988). Hydrogen peroxide metabolism in soybean embryonic axes at the onset of germination. Plant Physiol. 86, 626-630. doi: 10.1104/pp.86.2.626

Purvis, A. C., and Shewfelt, R. L. (1993). Does the alternative pathway ameliorate chilling injury in sensitive plant tissues? Physiol. Plant. 88, 712-718. doi: 10.1111/j.1399-3054.1993.tb01393.x

Rambaldi, D., and Ciccarelli, F. D. (2009). FancyGene: dynamic visualization of gene structures and protein domain architectures on genomic loci. Bioinformatics 25, 2281-2282. doi: 10.1093/bioinformatics/btp381

Rasmusson, A. G., Fernie, A. R., and van Dongen, J. T. (2009). Alternative oxidase: a defence against metabolic fluctuations? Physiol. Plant. 137, 371-382. doi: 10.1111/j.1399-3054.2009.01252.x

Rhoads, D. M., Umbach, A. L., Sweet, C. R., Lennon, A. M., Rauch, G. S., and Siedow, J. N. (1998). Regulation of the cyanide-resistant alternative oxidase of plant mitochondria - Identification of the cysteine residue involved in alphaketo acid stimulation and intersubunit disulfide bond formation. J. Biol. Chem. 273, 30750-30756. doi: 10.1074/jbc.273.46.30750

Rigas, S., Daras, G., Laxa, M., Marathias, N., Fasseas, C., Sweetlove, L. J., et al. (2009). Role of Lon1 protease in post-germinative growth and maintenance of mitochondrial function in Arabidopsis thaliana. New Phytol. 181, 588-600. doi: 10.1111/j.1469-8137.2008.02701.x

Robson, N. K. B. (1977). Studies in the genus Hypericum L. (Guttiferae): 1. Infrageneric classification. Bull. Br. Mus. Bot. 5, 291-355.

Rose, A. B., Elfersi, T., Parra, G., and Korf, I. (2008). Promoter-proximal introns in Arabidopsis thaliana are enriched in dispersed signals that elevate gene expression. Plant Cell 20, 543-551. doi: 10.1105/tpc.107.057190

Saisho, D., Nakazono, M., Lee, K. H., Tsutsumi, N., Akita, S., and Hirai, A. (2001). The gene for alternative oxidase-2 (AOX2) from Arabidopsis thaliana consists of five exons unlike other AOX genes and is transcribed at an early stage during germination. Genes Genet. Syst. 76, 89-97. doi: 10.1266/ggs.76.89

Saisho, D., Nambara, E., Naito, S., Tsutsumi, N., Hirai, A., and Nakazono, M. (1997). Characterization of the gene family for alternative oxidase from Arabidopsis thaliana. Plant Mol. Biol. 35, 585-596. doi: 10.1023/A:1005818507743

Santos, G. C., von Pinho, E. V. R., and Rosa, S. D. V. F. (2013). Gene expression of coffee seed oxidation and germination processes during drying. Genet. Mol. Res. 12, 6968-6982. doi: 10.4238/2013.December.19.16

Santos Macedo, E. S., Cardoso, H. G., Hernandez, A., Peixe, A. A., Polidoros, A., Ferreira, A., et al. (2009). Physiologic responses and gene diversity indicate olive alternative oxidase as a potential source formarkers involved in efficient adventitious root induction. Physiol. Plant. 137, 532-552. doi: 10.1111/j.13993054.2009.01302.x

Shih, M., and Goodman, H. M. (1988). Differential light regulated expression of nuclear genes encoding chloroplast and cytosolic glyceraldehyde-3-phosphate dehydrogenase in Nicotiana tabacum. EMBO J. 7, 893-898.

Smit A.F. A., Hubley, R., and Green, P. (2013-2015). RepeatMasker Open-4.0. Available online at: http://www.repeatmasker.org

Sytykiewicz, H. (2014). Differential expression of superoxide dismutase genes in aphid-stressed maize (Zea mays L.) seedlings. PLoS ONE 9:e94847. doi: 10.1371/journal.pone.0094847

Tamura, K., Dudley, J., Nei, M., and Kumar, S. (2007). MEGA4: Molecular Evolutionary Genetics Analysis (MEGA) software version 4.0. Mol. Biol. Evol. 24, 1596-1599. doi: 10.1093/molbev/msm092

Tan, Y. F., and Zhang, Q. F. (2001). Correlation of simple sequence repeat (SSR) variants in the leader sequence of the waxy gene with amylose content of the grain in rice. Acta Bot. Sin. 43, 146-150.

Umbach, A. L., Gonzalez-Meler, M. A., Sweet, C. R., and Siedow, J. N. (2002). Activation of the plant mitochondrial alternative oxidase: insights from site-directed mutagenesis. Biochim. Biophys. Acta 1554, 118-128. doi: 10.1016/S0005-2728(02)00219-0

Umbach, A. L., and Siedow, J. N. (1993). Covalent and noncovalent dimers of the cyanide-resistant alternative oxidase protein in higher plant mitochondria and their relationship to enzyme activity. Plant Physiol. 103, 845-854.

Vandesompele, J., De Preter, K., Pattyn, F., Poppe, B., Van Roy, N., De Paepe, A., et al. (2002). Accurate normalization of real-time quantitative RT-PCR 
data by geometric averaging of multiple internal control genes. Genome Biol. 3:RESEARCH0034. doi: 10.1186/gb-2002-3-7-research0034

Vanlerberghe, G. C. (2013). Alternative oxidase: a mitochondrial respiratory pathway to maintain metabolic and signaling homeostasis during abiotic and biotic stress in plants. Int. J. Mol. Sci. 14, 6805-6847. doi: 10.3390/ijms 14046805

Velada, I., Ragonezi, C., Arnholdt-Schmitt, B., and Cardoso, H. G. (2014). Reference genes selection and normalization of oxidative stress responsive genes upon different temperature stress conditions in Hypericum perforatum L. PLoS ONE 9:e115206. doi: 10.1371/journal.pone.0115206

Wang, C., Chen, S., and Yu, S. (2011). Functional markers developed from multiple loci in GS3 for fine marker-assisted selection of grain length in rice. Theor. Appl. Genet. 122, 905-913. doi: 10.1007/s00122-010-1497-0

Watanabe, C. K., Hachiya, T., Terashima, I., and Noguchi, K. O. (2008). The lack of alternative oxidase at low temperature leads to a disruption of the balance in carbon and nitrogen metabolism, and to an up-regulation of antioxidant defence systems in Arabidopsis thaliana leaves Identification of the T-DNA insertion in the. Plant Cell Environ. 31, 1190-1202. doi: 10.1111/j.13653040.2008.01834.x

Weitbrecht, K., Müller, K., and Leubner-Metzger, G. (2011). First off the mark: early seed germination. J. Exp. Bot. 62, 3289-3309. doi: 10.1093/jxb/err030

Yadav, C. B., Bonthala, V. S., Muthamilarasan, M., Pandey, G., Khan, Y., and Prasad, M. (2015). Genome-wide development of transposable elements-based markers in foxtail millet and construction of an integrated database. DNA Res. 22, 79-90. doi: 10.1093/dnares/dsu039

Yoshida, K., Terashima, I., and Noguchi, K. (2006). Distinct roles of the cytochrome pathway and alternative oxidase in leaf photosynthesis. Plant Cell Physiol. 47, 22-31. doi: 10.1093/pcp/ pci219

Yoshida, K., Terashima, I., and Noguchi, K. (2007). Up-regulation of mitochondrial alternative oxidase concomitant with chloroplast over-reduction by excess light. Plant Cell Physiol. 48, 606-614. doi: 10.1093/pcp/pcm033

Zanoli, P. (2004). Role of hyperforin in the pharmacological activities of St. John's Wort. CNS Drug Rev. 10, 203-218. doi: 10.1111/j.1527-3458.2004. tb00022.x

Zhang, L., Huang, J., Yang, N., Greshock, J., Megraw, M. S., Giannakakis, A., et al. (2006). microRNAs exhibit high frequency genomic alterations in human cancer. Proc. Natl. Acad. Sci. U.S.A. 103, 9136-9141. doi: 10.1073/pnas. 0508889103

Zuker, M. (2003). Mfold web server for nucleic acid folding and hybridization prediction. Nucleic Acids. Res. 31, 3406-3415. doi: 10.1093/nar/gkg595

Conflict of Interest Statement: The authors declare that the research was conducted in the absence of any commercial or financial relationships that could be construed as a potential conflict of interest.

Copyright (c) 2016 Velada, Cardoso, Ragonezi, Nogales, Ferreira, Valadas and Arnholdt-Schmitt. This is an open-access article distributed under the terms of the Creative Commons Attribution License (CC BY). The use, distribution or reproduction in other forums is permitted, provided the original author(s) or licensor are credited and that the original publication in this journal is cited, in accordance with accepted academic practice. No use, distribution or reproduction is permitted which does not comply with these terms. 